REMEDIATION OF SOIL HYDROPHOBICITY ON A COASTAL USGA SAND-BASED GOLF GREEN

\author{
A Thesis \\ presented to \\ the Faculty of California Polytechnic State University, \\ San Luis Obispo
}

\begin{abstract}
In Partial Fulfillment
of the Requirements for the Degree

Masters of Science in Agriculture, Specialization in Environmental Horticulture Science
\end{abstract}

by

Troy David Thompson

June 2010 
(C) 2010

Troy David Thompson

ALL RIGHTS RESERVED 
TITLE:

AUTHOR:

DATE SUBMITTED:

COMMITTEE CHAIR:

COMMITTEE MEMBER:

COMMITTEE MEMBER:
Remediation of Soil Hydrophobicity on a Coastal USGA Sand-Based Golf Green

Troy David Thompson

June 2010

Dr. Terry Vassey, Assistant Professor

Dr. Benali Burgoa, Associate Professor

Dr. Lynn Moody, Professor and Head of the Earth and Soil Sciences Department 


\section{ABSTRACT \\ Remediation of Soil Hydrophobicity on a Coastal \\ USGA Sand-Based Golf Green}

Troy David Thompson

Managing soil hydrophobicity caused by localized dry spots (LDS) on sand based golf greens has become one of the greatest challenges for golf course superintendents and managers, especially as water restrictions intensify. The purpose of this study was to evaluate the effectiveness of thirteen soil surfactants in eliminating LDS and in maximizing root zone soil moisture on a sand based USGA golf green located on the California Central Coast. Potential water repellency of air dried cores (measured utilizing the water droplet penetration time (WDPT) method), phytotoxicity, and climate were analyzed during two experimental trials. Phytotoxicity data was collected for Trial I using visual quality ratings and for Trial II using a chlorophyll meter. Phytotoxicity decreased during Trial I. Differences in phytotoxicity as measured using chlorophyll index were not at all significant during Trial II $(\mathrm{p}=1)$. Ten of the thirteen wetting agent treatments significantly $(\mathrm{p}<0.001)$ decreased soil hydrophobicity compared with the other wetting agent treated plots and the non-treated control. More frequent application of Cascade Plus resulted in a more significant reduction in soil hydrophobicity. Increasing the application rates also resulted in the reduction of soil hydrophobicity. Wetting agent treatment 6$\mathrm{CP}$ (10day) maintained the highest volumetric water content (VWC) but treatment 132079337 maintained the highest levels for wetting agents treated monthly. 


\section{ACKNOWLEDGEMENTS}

I would like to express sincerest appreciation to my committee chair, Dr. Terry Vassey, for the very fine opportunity to work on this project but more importantly for helping me to perform my work with a higher level of confidence. Dr. Vassey was also very patient with numerous questions. I would also like to thank the rest of my thesis committee, Dr. Benali Burgoa in Bio Resource and Agricultural Engineering and Dr. Lynn Moody in Earth and Soil Sciences for their specialized and invaluable guidance throughout this project. I would also like to thank Dr. Karen McGaughey for her statistical guidance and Wayne Montgomery for his assistance with reference material. Financial support for this project was provided by Aquatrols Corporation ${ }^{\circledR}$, Precision Laboratories $^{\mathrm{TM}}$, and Milliken ${ }^{\circledR}$. Finally, I would like to express thanks to my parents, William and Juliet Thompson, for their loving prayers and support, and to God for His constant support. 


\section{TABLE OF CONTENTS}

\section{Page}

LIST OF TABLES...................................................................

LIST OF FIGURES........................................................ii

\section{CHAPTER}

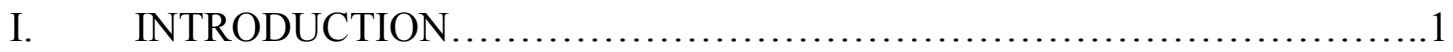

II. LITERATURE REVIEW ....................................................

III. METHODS AND MATERIALS ........................................

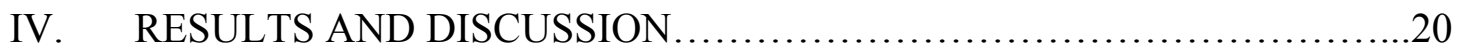

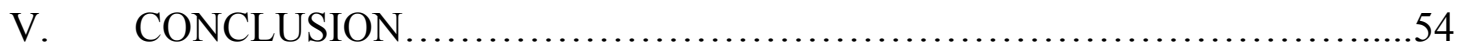

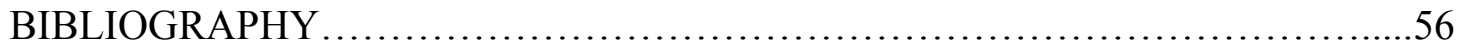

APPENDICES

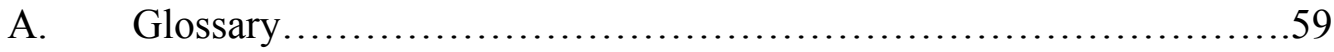

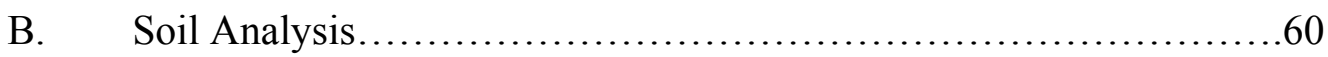
C. Control Soil Hydrophobicity and Trial I Analysis.....................64

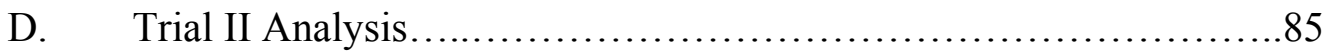
E. VWC Analysis.................................................. 130 


\section{LIST OF TABLES}

Table

1. Treatments for Trial I.............................................. 14

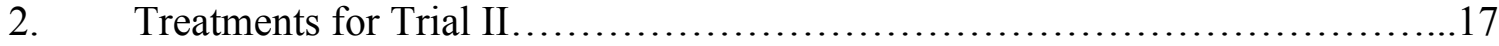

3. WDPT (seconds) of Aquatrols wetting agent treatments during Trial I (2008)

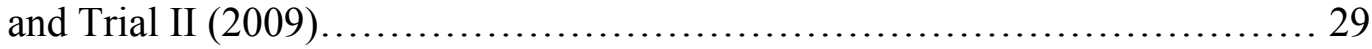

4. WDPT (seconds) compared by month during Trial I (2008) ................. 32

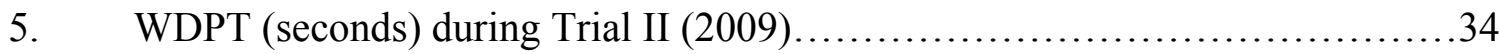

6. Comparison of treatments with control during Trial II (2009)..................35

7. WDPT (seconds) compared by depth during Trial I (2008)....................37

8. WDPT (seconds) compared by depth during Trial II (2009).................39

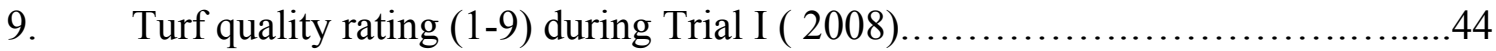

10. Percent spread of LDS during Trial I (2008) ............................45

11. ANOVA table for chlorophyll index values.............................. 47

12. Precipitation data from irrigation heads during irrigation audit (mm per hour)...49

13. Percent VWC during Trial II (2009)......................................... 
Figure

\section{LIST OF FIGURES}

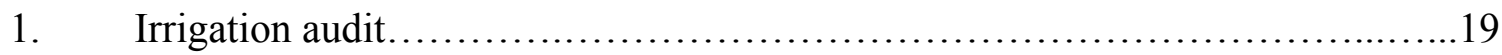

2. Irrigation heads in relation to the green...................................

3. Soil analysis in the top $12 \mathrm{~cm}$ of the green root zone........................20

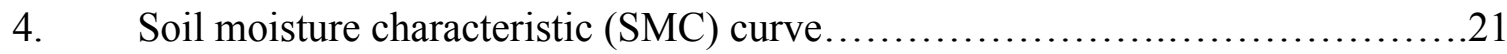

5. Soil hydrophobicity of untreated control plots during 2008 and 2009 ...........22

6. Maximum air temperature from CIMIS (averaged 30 days prior to core extraction) during Trial I (2008) and during Trial II (2009)....

7. Green root zone soil temperature and surface ambient temperature obtained using soil thermometer during Trial II (2009)...

8. Volumetric water content (VWC) of untreated control plots obtained using a time domain reflectometer at 5.8 and $12 \mathrm{~cm}$ deep.......................25

9. Evapotranspiration (ET) requirements of the green and estimated precipitation including rainfall ..................................................... 27

10. Maximum relative humidity from CIMIS during Trial I (2008) and during

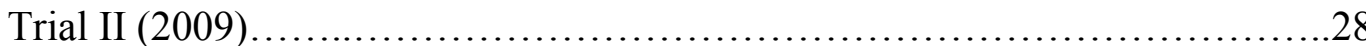

11. Water droplet penetration time (WDPT) of plots treated with Aquatrols (ACA) treatments during Trial I (2008). The five arrows indicate the five wetting agent applications dates........................................... 30

12. Water droplet penetration time (WDPT) of plots treated with Aquatrols (ACA) treatments during Trial II (2009). The six arrows indicate the six wetting agent application dates 
13. Water droplet penetration time (WDPT) of treated and untreated plots during Trial II (2009). Treatment application dates are indicated by arrows. The exception being 6-CP(10day) and 7-CP(60day) which were applied every 10 days and every 60 days respectively. 33

14. WDPT (seconds) for each depth (average of all dates) during Trial I (2008).....36

15. WDPT (seconds) for each depth (average of all dates) during Trial II (2009)....38

16. Comparison of wetting agent treatment trends at individual depths during

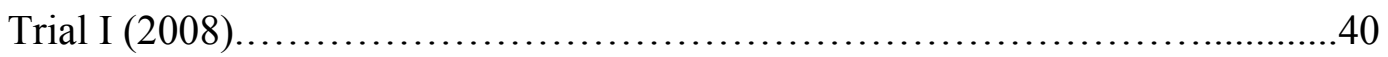

17. Comparison of top five performing wetting agents at individual depths during

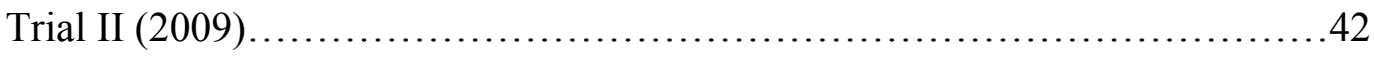

18. Turf quality rating (1-9) during Trial I (2008). 1=yellow, 9=dark green.........43

19. Percent spread of localized dry spots (LDS) during Trial I (2008).................44

20. Chlorophyll index values arranged themselves by month rather than by

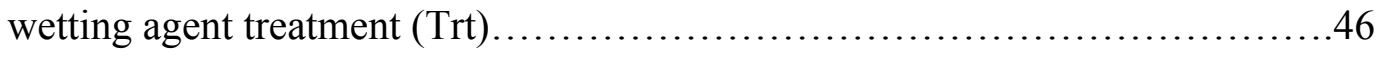

21. Spatial variability map of catch can lower quartile distribution uniformity .......48

22. Results from irrigation audit......................................... 50

23. Treatments with significantly lower percent volumetric water content (VWC) than treatment with the highest VWC (6-CP10day), FC = field capacity, $\mathrm{PWP}=$ permanent wilting point.

24. Treatments with significantly greater percent volumetric water content (VWC) than treatment with the lowest VWC (2-ACA 2787), FC = field capacity, $\mathrm{PWP}=$ permanent wilting point. 


\section{CHAPTER 1}

\section{INTRODUCTION}

The management of soil hydrophobicity, the impermeability of a soil to wetting by water, has become one of the greatest challenges for golf course superintendents, especially in regions facing water shortages. Soil hydrophobicity causes localized dry spots (LDS) to appear on sand based golf putting greens causing turfgrass to become severely wilted and more susceptible to disease (Jaramillo et al., 2000). The spread of soil hydrophobicity on a golf course green often goes unnoticed as subtle, irregular dew patterns later turning to LDS upon soil dry down (Wallis et al., 1989). These patterns vary in size and shape and are influenced largely by small irregularities in irrigation uniformity (Wallis et al., 1989). These areas actually remain re-wettable unless allowed to dry beneath a critical soil water content (Dekker et al., 1998).

Coming in contact with each other, organic carbon coatings on the outer surface of sand particles form a hydrophobic seal preventing irrigation water from infiltrating and, ultimately, from wetting the soil particles (Dekker et al., 1998). Extreme drying temperatures may result in an even greater increase in the formation of these organic coatings responsible for soil hydrophobicity. When soil becomes irreversibly dry, routine frequent irrigations will tend to cause excess runoff or cause water to become unevenly dispersed in the root zone.

Soil hydrophobicity is most severe in the top 2.5 to $5 \mathrm{~cm}$ of the root zone (Karnok and Tucker, 2002). This is caused by the buildup of organic matter residues near the surface as tissue from dead root materials begin to occupy soil macropores. This buildup depletes the oxygen needed for root health (O’Brien and Hartwiger, 2003). 
The primary objective of this research was to evaluate the effectiveness of thirteen soil surfactants in alleviating soil hydrophobicity, localized dry spots and phytotoxicity caused on a United States Golf Association (USGA) sand based golf green on the California Central Coast. A second key objective of this study was to calculate the correct volumetric water content (VWC) range for irrigation on the sand based putting green used in this study, and to determine which wetting agent treatment retains the greatest amount of moisture (VWC) in the root zone. The primary objective was met using water droplet penetration time (WDPT) of sample cores to determine severity of soil hydrophobicity, visual observations to determine the percent coverage of localized dry spots, a qualitative turf quality test and a chlorophyll meter to determine phytotoxicity. Ideal VWC for the sand based putting green was calculated by performing a soil water tension test and actual VWC was measured using a Time Domain Reflectometer. This project was necessary to determine the performance of wetting agents in a coastal climate. This project is a product registration test for Aquatrols Corporation ${ }^{\circledR}$, Milliken ( , and Precision Laboratories ${ }^{\mathrm{TM}}$. 


\section{CHAPTER 2}

\section{REVIEW OF LITERATURE}

\section{Introduction}

The management of soil hydrophobicity, or impermeability of water into soil, has become one of the greatest challenges for golf course superintendents especially in regions facing water shortages. Soil hydrophobicity causes localized dry spots (LDS) to appear on sand based golf putting greens causing turfgrass to become severely wilted and more susceptible to disease (Jaramillo et al., 2000). The spread of soil hydrophobicity on a golf course green often goes unnoticed as subtle, irregular dew patterns later turning to LDS upon soil dry down (Wallis et al., 1989). These patterns vary in size and shape and are influenced largely by small irregularities in irrigation uniformity (Wallis et al., 1989). These areas remain re-wettable unless allowed to dry beneath a critical soil water content (Dekker et al., 1998).

\section{$\underline{\text { Soil Characteristics }}$}

Soil textural composition probably has the greatest effect on soil hydrophobicity. Because of the necessity to prevent compaction stress and to increase infiltration and drainage, the United States Golf Association (USGA) recommended that green rootzones be constructed with at least 90 percent sand which is by definition a USGA sand based green (Hummel, 1993).

The correlation between the original sand content used in greens construction and localized dry spots (LDS) was studied at four Georgia golf courses. The greens at two courses (Hidden Hills and Summit Chase) were treated with wetting agents while the 
greens at two other courses (Fairfield Plantation and Peachtree Golf Club) were not (Tucker et al., 1990). On untreated greens, researchers found a significantly lower percentage of LDS in greens composed of 84.6 percent sand compared to greens composed of at least 93.9 percent sand (Tucker et al., 1990). The use of wetting agents on greens with sand contents greater than 90 percent at Hidden Hills and Summit Chase, decreased the percentage of LDS to levels similar with the untreated greens having 84.6 percent sand at Fairfield Plantation (Tucker et al., 1990).

Scanning electron micrographs of individual sand particles taken from localized dry spots revealed a coating having the appearance of fungal mycelium that is organic and acidic in nature (Wilkinson and Miller, 1978). Infrared spectra of the organic coatings (obtained using a Perkin Elmer Infrared Spectrophotometer), were similar in appearance to the spectrum for fulvic acid (Wilkinson and Miller, 1978). Fulvic acid is a water repellent organic acid polymer, which can be isolated from humus at $\mathrm{pH}=1$ (Tan, 1998). It was speculated that $\mathrm{Ca}$ and $\mathrm{Mg}$ fulvates form after sand based soils dry out as a result of high organic matter accumulation (Wilkinson and Miller, 1978). However, other studies have shown there to be no evidence of extractable $\mathrm{Ca}$ or $\mathrm{Mg}$ in localized dry spots (Tucker et al., 1990). Although no specific fungus was isolated as the cause of soil hydrophobicity, basidiomycete sporocarp/hyphal colonies were observed (Wilkinson and Miller, 1978).

Another very important soil characteristic that contributes to soil hydrophobicity is soil $\mathrm{pH}$. Acidic soils tend to have greater occurrences of hydrophobicity than alkaline soils (Karnok et al., 1993). It has been shown that high $\mathrm{pH}$ treatments $(\mathrm{NaOH})$ applied to a hydrophobic experimental Bentgrass putting green resulted in a significant reduction in 
soil hydrophobicity (Karnok et al., 1993). These observations suggest that soil hydrophobicity may be dependent on moderate to high soil acidity. Unfortunately, when $\mathrm{NaOH}$ was applied during warmer temperatures $\left(>30 \mathrm{C}^{\circ}\right)$, these high $\mathrm{pH}$ applications caused severe phytotoxicity taking longer than a year for the turf to fully recover (Karnok et al., 1993).

\section{$\underline{\text { Microbial Activity }}$}

Certain basidiomycetous fungi also cause soil hydrophobicity. Fairy ring fungi (most commonly Marasmius oreades) have long been identified as causing water repellency in turf. Over fifty species are capable of forming fairy rings classified into three types (Couch, 1995).

All three types of fairy ring start from mycelia fragments or basidiospores that withdraw nutrients from organic matter and expand through mycelia growth in all directions forming a "hyphal knot". Type I fairy ring initially stimulates grass growth but eventually causes the grass to die. Fungus mycelia saprophytically reduce the protein portion of organic matter to ammonia which if not diluted with water causes root burn. Bacteria eventually convert ammonia to nitrates stimulating the grass to form a darker green ring. When the stimulated grass root zone becomes fully colonized by mycelia, the soil becomes hydrophobic. As a result, the stimulated growth cannot be sustained due to lack of water thus death of the grass occurs. Similar to Type I fairy ring, Type II fairy ring also stimulates grass growth as seen by darker green circles or arcs. Unlike Type I however, Type II fairy ring does not harm the grass (Couch, 1995). Finally, Type III fairy rings produces mushrooms but are harmless to grass (Fidanza et al., 2007). 
The first two types are associated with severe to moderate soil hydrophobicity (Fidanza et al., 2007). Fairy ring fungi can continue living under dry conditions by either going dormant or by leaving behind their spores but cannot survive without adequate oxygen in the rootzone (Coyne, 1999). The thick mycelial mat barrier found in association with fairy ring symptoms was believed to be the sole cause of soil hydrophobicity (Wilkinson and Miller, 1978).

Researchers at UC Riverside found that mixing a wetting agent with fungicide treatments reduced fairy ring symptoms compared to the use of fungicides alone (Fidanza et al., 2007). Using a Bentgrass putting green with type I and type II fairy ring, they applied Endorse, Insignia, Heritage and Prostar fungicides independently as well as in a tank-mix with the wetting agent Revolution (Aquatrols ${ }^{\circledR}$ Corporation, Paulsboro, NJ). Treatments were applied at 7.6 liters or 15.1 liters of water per 93 square meters. (Fidanza et al., 2007).

Sixty days after treatment, three of the four fungicide treatments showed significantly less fairy ring symptoms when mixed with a wetting agent whether in 7.6 liters or 15.1 liters of water. With the exception of Insignia, the fungicide treatments applied without a wetting agent in 15.1 liters of water exhibited greater reduction of fairy ring symptoms than when applied using 7.6 liters of water. They concluded that the wetting agent helped to improve the effectiveness of the fungicide treatment (Fidanza et al., 2007).

A similar study was conducted using the wetting agent Primer (Aquatrols $\AA$ Corporation) and Flutolanil as the fungicide (Karnok and Tucker, 2001). While Flutolanil 
reduced the growth of fairy ring, it had no effect on soil hydrophobicity without the wetting agent.

\section{Management}

The neglect of routine turf management practices (i.e. aeration, topdressing, fertilization, and protection against traffic stress) also may cause soil hydrophobicity and localized dry spots. Core aerations allow oxygen and water to reach the tips of roots and help to keep the grass from dying in hydrophobic soil. Topdressing with sand helps with the dilution of organic matter in the rootzone and with the protection of aeration holes against macropore clogging debris. Core aeration and topdressing are considered the two most effective means of controlling organic matter content in turf soil (O'Brien and Hartwiger, 2003).

Traffic (or compaction) stress may actually be the severest of stresses depending on other soil conditions. Fertilization with increased nitrogen levels may offer some relief depending on the severity but can cause higher levels of organic matter in the surface soil profile. Because organic material retains more moisture, the soil becomes softer and more vulnerable to traffic stress (O’Brien and Hartwiger, 2003).

\section{$\underline{\text { Climate }}$}

In addition to management practices, climatic factors also influence soil hydrophobicity. Temperature, precipitation, and humidity effect soil hydrophobicity directly during soil dry down and indirectly depending on plant species (in our case spp. Bentgrass, Agrostis palustris L. 'Penncross').

The influences of precipitation and temperature on hydrophobicity were tested at two locations in South Australia (Franco et al., 2000). The top $15 \mathrm{~cm}$ (homogenous 
siliceous sand horizon) were sampled over a 28-month period and tested for hydrophobicity using the Molarity of an Ethanol Droplet (MED) test (Franco et al., 2000). Soil hydrophobicity peaked during the dry summer months most likely because of unfavorable conditions for wax degrading microorganisms (Franco et al., 2000) and because of the increased chance of soil dry down (Wilkinson and Miller, 1978).

High temperatures cause an imbalance in photosynthesis and respiration, which often leads to carbohydrate depletion in the roots (Carrow, 1996). As roots have lower priority than shoots, roots can be sacrificed during stress to supply shoots with carbohydrates. As a result of losses in root mass, and eventual losses in nutrient and water uptake, the roots produce less cytokinin. Lower cytokinin causes a disruption in the regulation of cell division, shoot formation, and premature senescence. It is at this point that root cells lose their structure and rupture, producing a gel-like substance in the root zone. This gel-like substance clogs adjacent soil macropores and replaces $\mathrm{O}_{2}$ causing the problem to spread. Watering more frequently in an effort to revitalize the turfgrass may actually compound the problem by further depleting what little $\mathrm{O}_{2}$ is left. Because high temperatures cause an increased demand for $\mathrm{O}_{2}$ used for both root respiration as well as for soil microorganisms, the problem for root metabolism is compounded resulting in rapid root dieback or Summer Bentgrass Decline (Carrow, 1996).

There are also profound effects of humidity and precipitation on soil hydrophobicity. Actual water repellency (field moist samples) and potential water repellency (air dried samples) of sand based soils taken from Middle Rio Basin, New Mexico and from the Piedras Blancas Watershed in Columbia, South America were examined (Jaramillo, et al., 2000). The Middle Rio Basin is very arid with an 
evapotranspiration rate ten times that of its mean annual precipitation (elevation $\sim 1400$ $m)$. The Piedras Blancas Watershed by contrast is very humid (74-98 \%) and has an evapotranspiration rate half that of its mean annual precipitation (elevation 2340-2680 $\mathrm{m})$.

A comparison at these two locations revealed that extremely humid climates are perhaps more apt to develop water repellency despite ample amounts of rainfall where extremely arid climates do not. The effect of climate on the development of water repellency may be limited primarily to its effect on the production of organic matter (Jaramillo et al., 2000). Because water and dead organic matter is required for the active production of hydrophobic substances by microorganisms, the spread of soil hydrophobicity may be lessened if water is deficient.

In contrast, Horne and McIntosh (2000) describe four possible mechanisms of soil hydrophobicity caused by decreased water in the soil. First, amphipathic compounds surrounding the outer layer of the organic coatings surrounding soil particles may become re-oriented. In a wettable soil, the polar group of the amphipathic compound points outward. If these compounds are re-configured (i.e. during soil dry-down), the amphipathic compounds flip ends causing their water repellent end (group) to become exposed.

Second, the ionization status of the carboxylic groups within amphipathic compounds can affect soil hydrophobicity depending on soil $\mathrm{pH}$ and moisture. Third, soil hydrophobicity may develop when hydrophobic compounds are more exposed. Finally, the extraction or addition of compounds (i.e. surfactants) may change repellency (Horne and McIntosh, 2000). 


\section{Use of Surfactants to Alleviate Localized Dry Spots}

Surface active agents (surfactants) contain polar and non-polar molecules which are able to link hydrophobic soil with water and other polar substances (Karnok et al., 2004). A wetting agent is a surfactant that is used to wet a solid or a liquid by allowing its non-polar molecule to become adsorbed (bonded) to the other non-polar substance so that the polar molecule can help absorb water. To minimize phytotoxicity, most wetting agents are non-ionic and do not react with ions in the soil to form salts.

Wetting agents have many uses including the dispersion of water for increased irrigation efficiency (Karnok, 2008) and the leaching of hydrophobic (water repellent) materials through the root zone (Karnok et al., 2004). Surfactants also improve infiltration of applied irrigation (Karnok and Tucker 2001) even when less water is used (Franklin et al., 2005). Random samples taken from 36 USGA sand based tees in Massachusetts indicated that surfactant treatments established matrix flow and improved the uniformity of irrigation water in the soil profile (Kostka, 2000).

Increasing surfactant rate reduces water repellency more rapidly, and the systematic application of surfactants can aid in the elimination of localized dry spots (Kostka, 2000). Monthly applications of wetting agents help to maintain adequate surfactant levels in the soil (Miller, 2001). Reductions in water repellency have been observed in plots treated with the wetting agent Primer 604 regardless of turf type, soil, or climate (Kostka, 2000). However, surfactant adsorption near the surface has been shown to reduce the amount of surfactant reaching the greater depths (Feng et al., 2002).

Studies have been conducted comparing application intervals (Miller, 2001), application rates (Carey and Gunn, 2004) or both (Leinauer et al., 2007). Applications 
made more frequently provided better season long protection against soil hydrophobicity than less frequent applications (Miller, 2001). Increasing the amount of wetting agent applied to the same area (application rate) reduced soil hydrophobicity in some cases (Cary and Gunn, 2004; Kostka et al., 1997) but had no effect in other cases (Miyamoto, 1985). A conglomeration of studies conducted throughout the United States compared the same wetting agents by climatic region (Throssel, 2005) and found that Cascade Plus consistently reduced soil hydrophobicity more than the other wetting agents compared.

In review, wetting agents are surfactants having both polar and non-polar molecules that link hydrophobic non-polar materials with water and other polar substances. The effectiveness of a particular wetting agent in alleviating soil hydrophobicity is in large part determined by soil characteristics, microbial activity, climate, and the chemistry of the wetting agent. High $\mathrm{pH}$ treatments can alleviate hydrophobicity but often causes phytotoxicity. While certain native microorganisms may consume hydrophobic substances, this has only been shown to occur in the absence of plants. Soil hydrophobicity may worsen with warm temperatures causing soil dry down but also persists in humid climates despite ample rainfall.

The objective of the following study is to evaluate the effectiveness of thirteen wetting agent treatments in alleviating hydrophobic localized dry spots on a coastal Bentgrass golf green in relation to climate changes and possible microbial stress. A second key objective of this study is to determine which surfactant retains the greatest amount of moisture (VWC) in the root zone, and to calculate the volumetric water content (VWC) that maximizes the availability of both water and oxygen to the roots of sand based putting greens. 


\section{CHAPTER 3}

\section{METHODS AND MATERIALS}

\section{$\underline{\text { Species Studied }}$}

Creeping Bentgrass (Agrostis stolonifera, L.; 'Palustris', Huds.) is a stoloniferous grass belonging to the Aveneae tribe (Turgeon, 2005). Originally selected by the USGA Green Section it has become the most widely used cool season grass for golf greens. Agrostis stolonifera is a tetraploid with 28 chromosomes $(2 \mathrm{n}=4 \mathrm{x}=28)$. Three vegetatively propagated clonal strains of creeping bentgrass were hybridized to develop Penncross ('Palustris', Huds.), the variety used in this study.

Annual Bluegrass, although considered a weed, makes up approximately 35 percent of the green used in this study. Annual Bluegrass (Poa annua L.) is a bunch type grass belonging to the Poeae tribe and can become a major component of some intensively cultured turfgrass communities (Turgeon, 2005). No attempt to remove this species has ever been made on the green used in this study.

\section{$\underline{\text { Soil Analysis }}$}

To test for actual soil hydrophobicity two samples $5 \mathrm{~cm}$ deep were obtained from the green used in this study Using a turf profiler. Drops of water were applied to the samples and classified as hydrophobic at greater than 10 seconds penetration time. Twelve cores, $12 \mathrm{~cm}$ in length were extracted from a hydrophobic area (also representative of Trial II-2009) and from an area representative of the entire green (Trial I-2008). The 12 cores from each area were mixed separately and submitted to Precision Agri Lab (Madera, CA) for soil analysis prior to the start of the experiment. 


\section{Volumetric Water Content (VWC) Range for the Green}

A soil water tension curve was generated using values for volumetric water content at saturation, field capacity, and permanent wilting point (ASTM, 2008). Four 6 $\mathrm{cm}$ long cores $(5.4 \mathrm{~cm}$ in diameter) were collected from five different areas spaced across the green using a soil core sampler. Sample rings representative of the surface $3 \mathrm{~cm}$ of the root zone were separated from sample rings representative of 3 to $6 \mathrm{~cm}$ using a knife to make 40 samples. De-ionized water was added to samples and allowed to saturate by capillarity action. Weight of soil at saturation was obtained by weighing the 0.33 bar samples prior to placement in the pressure plate. Four samples from each area of the green were placed in pressure plates set at $0.05,0.1,0.33$, and 15 bars pressure, respectively. After water extraction was complete for each pressure plate, the samples were weighed to obtain wet weight.

Approximately $1 / 3$ of each sample was scooped into pre-weighed metal cans, weighed again, and oven dried. An exception was made for field capacity ( 0.33 bars $)$ in which samples were placed ring and all inside larger pre-weighed metal cans weighed and oven dried. All samples were weighed to obtain oven dry weight at the end of the experiment. The purpose was to calculate bulk density, subsequently used to convert water content by weight (gravimetric water content) to volumetric water content (VWC). The four sample results at two depths from the five areas of the green (40 samples total) were used in the following equations (1-3) and averaged to find the VWC corresponding to each water tension level. This data was used to calculate a Soil Moisture Characteristic Curve. 
$\% \mathrm{H}_{2} \mathrm{O}$ by $\mathrm{wt}=\underline{(\mathrm{wt} \text { can }+ \text { lid }+ \text { moist soil }-\mathrm{wt} \text { can }+ \text { lid }+ \text { oven dry soil })} \times 100$

(wt of can + lid + oven dry soil - wt of can + lid)

$$
\text { Bulk Density }=\frac{(\text { Oven dry weight }- \text { can }- \text { ring })}{70.96 \mathrm{~cm}^{3} *}
$$

$$
\mathrm{VWC}=\% \mathrm{H}_{2} \mathrm{O} \text { by weight } \times \text { Bulk Density }
$$

*The volume of the soil samples was derived by multiplying $\operatorname{ring}$ area $\left(\mathrm{r}^{2} \pi\right)$ by ring height.

\section{$\underline{\text { Experimental Trial I (2008) }}$}

An initial experimental trial was conducted on the Cal Poly research green comparing five plots treated with different surfactants (supplied by Aquatrols ${ }^{\circledR}$ ) and a non-treated control. The experiment was laid out as a randomized complete block design with four replicates. Six 1 x 1-1/2 m plots were marked out per replicate with a $0.6 \mathrm{~m}$ buffer zone between replicates and a $0.3 \mathrm{~m}$ buffer down the center of each replicate lengthwise to prevent overspray. Until all data had been collected, treatments were

\begin{tabular}{|c|c|c|c|c|}
\hline $\begin{array}{l}\text { Treatment } \\
\text { No. }\end{array}$ & Company & Material & $\begin{array}{c}\text { Mix }(\mathrm{ml}) / \\
110 \mathrm{ml} \mathrm{H} \mathrm{H}_{2} \mathrm{O}\end{array}$ & $\begin{array}{c}\text { Application } \\
\text { rate }(\mathrm{ml}) / 93 \mathrm{~m}^{2}\end{array}$ \\
\hline 1 & Aquatrols & ACA 1820- Revolution & 3 & 200 \\
\hline 2 & Aquatrols & ACA 2787 & 3 & 200 \\
\hline 3 & Aquatrols & ACA 2892 & 0.5 & 33 \\
\hline 4 & Aquatrols & ACA 2893 & 0.5 & 33 \\
\hline 5 & Aquatrols & ACA 1848- Dispatch & 0.5 & 33 \\
\hline 6 & - & Control & - & - \\
\hline
\end{tabular}
identified by code. Application rates are listed in Table 1.

Table 1. Treatments for Trial I

With the exception of aeration (which was beyond the scope of this study), routine green maintenance was performed. The green was mowed every Monday through Friday during morning hours and verticut once a month prior to mowing. The green was irrigated Saturday, Sunday, and Wednesday for an average of 12 minutes for perimeter 
heads starting in May (24 minutes for the center head) and was increased to 14 minutes for perimeter heads during July (29 minutes for center head). The green was fertilized once in the Summer (29 July 2008) with "Country Club" 3/4 lb. N (18-3-18), 7.2\% as water soluble $\mathrm{N}$ (methylene ureas) and $4.5 \%$ as insoluble $\mathrm{N}$. The green was also treated with Scintar/Quicksilver 23 September 2008 to control an incidence of cut worm.

Treatments were hand sprayed 1 May 2008 and again every 30 days for six months and immediately hand watered until turf appeared glossy. Applications were spaced 30 days apart to maintain adequate amounts of wetting agent in the soil (Miller, 2001). Five $8 \mathrm{~cm}$ long cores (1.27 $\mathrm{cm}$ in diameter) were taken from each plot just prior to applying the next monthly application.

The Water Droplet Penetration Time (WDPT) test was selected as the most effective means of measuring potential soil hydrophobicity and most closely associated with the contact angle as obtained by both the capillary rise and sessile drop methods (Leelamanie et al., 2008; King, 1981).

To isolate the effect that soil moisture has on soil hydrophobicity the cores were air dried in a laboratory for 2 weeks prior to testing for potential soil hydrophobicity using the WDPT test. A $35-\mu \mathrm{L}$ drop of deionized water was applied to each core using a pipette. Drops were applied starting at the grass/organic matter surface interface and at one-centimeter intervals to a depth of five centimeters (six droplets per core). The time required for the droplets to be absorbed was recorded in seconds.

Significance for the effect of treatment on WDPT was analyzed by conducting a one-way analysis of variance (in Minitab). The null hypothesis was that there would not be a significant difference in WDPT among the wetting agent treatments. The condition 
of normality for WDPT was satisfied by performing a log transformation of the original data. The Tukey method was used to find which wetting agent treatments significantly decreased soil hydrophobicity. To minimize the risk of stating a false positive (declaring a treatment worse or better when it is not), the Tukey method tests the individual comparisons at a higher confidence level $(99.92 \%)$ to arrive at a total confidence level of 95 percent for all pairwise comparisons.

Every week starting 6 March 2008, plots were rated 1 through 9 (1=yellow, $9=$ dark green) to measure phytotoxicity. Starting 15 July 2008, 10 chlorophyll index values were collected from each plot per week using a CM 1000 (Spectrum Technologies, Plainfield, IL) in an attempt to provide a quantitative measurement of phytotoxicity.

\section{$\underline{\text { Experimental Trial II (2009) }}$}

A second experimental trial was carried out on a different part of the same green also determined to be hydrophobic. Thirteen different treatments per replicate plus the control were compared. This experiment was a randomized complete block design with four replicates. Fourteen 1 x 1-1/2 m plots were marked out per replicate with a $0.6 \mathrm{~m}$ buffer zone between each replicate. The treatments included the five treatments from Experiment I, plus four treatments from Precision Laboratories ${ }^{\mathrm{TM}}$ (Waukegan, IL), and four treatments from Milliken ${ }^{\circledR}$ (Spartanburg, SC).

Plots were first hand sprayed on 26 February 2009; and, with the exception of two treatments, they were treated every 30 days for six months. The two exceptions were Cascade Plus, which was applied every 10 days and every 60 days. Application rates are listed in Table 2. 
Table 2. Treatments for Trial II.

\begin{tabular}{|c|c|c|c|c|}
\hline $\begin{array}{l}\text { Treatment } \\
\text { No. }\end{array}$ & Company & Material & $\begin{array}{c}\operatorname{Mix}(\mathrm{ml}) / \\
110 \mathrm{ml} \mathrm{H} \mathrm{H}_{2} \mathrm{O}\end{array}$ & $\begin{array}{c}\text { Application rate } \\
(\mathrm{ml}) / 93 \mathrm{~m}^{2}\end{array}$ \\
\hline 1 & Aquatrols & ACA $1820-$ Revolution & 3 & 200 \\
\hline 2 & Aquatrols & ACA 2787 & 3 & 200 \\
\hline 3 & Aquatrols & ACA 2892 & 0.5 & 33 \\
\hline 4 & Aquatrols & ACA 2893 & 0.5 & 33 \\
\hline 5 & Aquatrols & ACA 1848 -Dispatch & 0.5 & 33 \\
\hline 6 & Precision & $\begin{array}{l}\text { Cascade Plus } 10 \text { day } \\
\text { interval }\end{array}$ & 3.5 & 233 \\
\hline 7 & Precision & $\begin{array}{l}\text { Cascade Plus } 60 \text { day } \\
\text { interval }\end{array}$ & 3.5 & 233 \\
\hline 8 & Precision & Magnus & 1.5 & 100 \\
\hline 9 & Precision & $\begin{array}{l}\text { Magnus mixed with } \\
\text { Duplex }\end{array}$ & $\begin{aligned} & 1.3 \\
+ & 0.375\end{aligned}$ & $\begin{array}{r}87 \\
+25\end{array}$ \\
\hline 10 & Milliken & $\begin{array}{l}20793365 \mathrm{ml} / 110 \mathrm{ml} \\
\mathrm{H}_{2} \mathrm{O}\end{array}$ & 5 & 333 \\
\hline 11 & Milliken & $\begin{array}{l}20793368 \mathrm{ml} / 110 \mathrm{ml} \\
\mathrm{H}_{2} \mathrm{O}\end{array}$ & 8 & 533 \\
\hline 12 & Milliken & $\begin{array}{l}20793375 \mathrm{ml} / 110 \mathrm{ml} \\
\mathrm{H}_{2} \mathrm{O}\end{array}$ & 5 & 333 \\
\hline 13 & Milliken & $\begin{array}{l}20793378 \mathrm{ml} / 110 \mathrm{ml} \\
\mathrm{H}_{2} \mathrm{O}\end{array}$ & 8 & 533 \\
\hline 14 & - & Control & - & - \\
\hline
\end{tabular}

The same testing procedure for WDPT and routine greens maintenance was followed as in Experimental Trial I. Mowing height was increased from 0.110 inch to 0.170 inch on 2 July 2009. The green was irrigated 3 days a week 4 minutes per head starting in March (7 minutes for center head) and gradually increased to 15 minutes per head during July (30 minutes for center head). The green was fertilized on 19 March 2009 with $1 / 2$ lb. N (13-2-16) and with $1 \frac{1}{2}$ lb. N (5-2-5) 200 with $10 \%$ Fe. Wettergrans: Greens Grade granular surfactant was applied the same day to the entire green at 2 $\mathrm{kg} / 100 \mathrm{~m}^{2}$ to aid the green in uptake of the fertilizer.

Soil moisture was recorded weekly at depths 0 to $5.8 \mathrm{~cm}$ and 0 to $12 \mathrm{~cm}$ using a Field Scout ${ }^{\circledR}$ time domain reflectometer (Spectrum Technologies, Plainfield IL). The 
green was dried down below field capacity in April and June to control algae growth. Soil temperature was also recorded weekly at a depth of $2 \mathrm{~cm}$ and $10 \mathrm{~cm}$. Starting 18 March 2009 Chlorophyll index values were collected every 10 days prior to the application of surfactants using a chlorophyll meter (CM 1000 from Spectrum Technologies) to measure phytotoxicity. Maximum air temperature and humidity was obtained from the California Irrigation Management Information System (CIMIS) Station 052 in San Luis Obispo located on the California Polytechnic State University campus less than one mile from the experimental green. High air temperatures were averaged 30 days prior to core extraction dates to obtain maximum air temperature. Green evapotranspiration (ET) was calculated by multiplying CIMIS daily reference evapotranspiration $\left(\mathrm{ET}_{\mathrm{O}}\right)$ with crop coefficient $\left(\mathrm{K}_{\mathrm{C}}\right)$ multipliers obtained from Gibeault et al. (1989).

Significance was determined using a one-way Analysis of Variance (ANOVA). The Tukey method was used to compare water drop penetration time (WDPT) among treatments. The condition of normality for WDPT was satisfied using the quadratic root transformation of the original data. Comparison of WDPT by month and also by depth was analyzed using a repeated measures analysis General Linear Model (GLM). Overall turf quality and percent coverage of LDS data from Trial I was analyzed and compared using an ANOVA and Tukey Confidence Intervals, respectively. Index values for the Trial II were also analyzed using an ANOVA. The effect of wetting agent treatment on root zone volumetric water content was analyzed using an ANOVA and treatments were compared constructing Tukey Confidence Intervals.

A catch can irrigation audit as outlined by Kieffer (2007) was performed to calculate lower quartile irrigation distribution uniformity $\left(\mathrm{DU}_{\mathrm{lq}}\right)$. Catch can gauges were 
placed between irrigation heads in a straight line and each head was run separately for fifteen minutes to maintain adequate pressure (Figure 1). This procedure was followed for the four peripheral heads closest to head 5 in the center of the green (Figure 2). All heads were rotor Rainbird (Tucson, AZ) Eagle 750s except for Head 5 which was an Eagle 700. The average of the lowest fourth of all catch can readings was divided by the average of all catch can readings to obtain lower quartile distribution uniformity $\left(\mathrm{DU}_{\mathrm{lq}}\right)$.

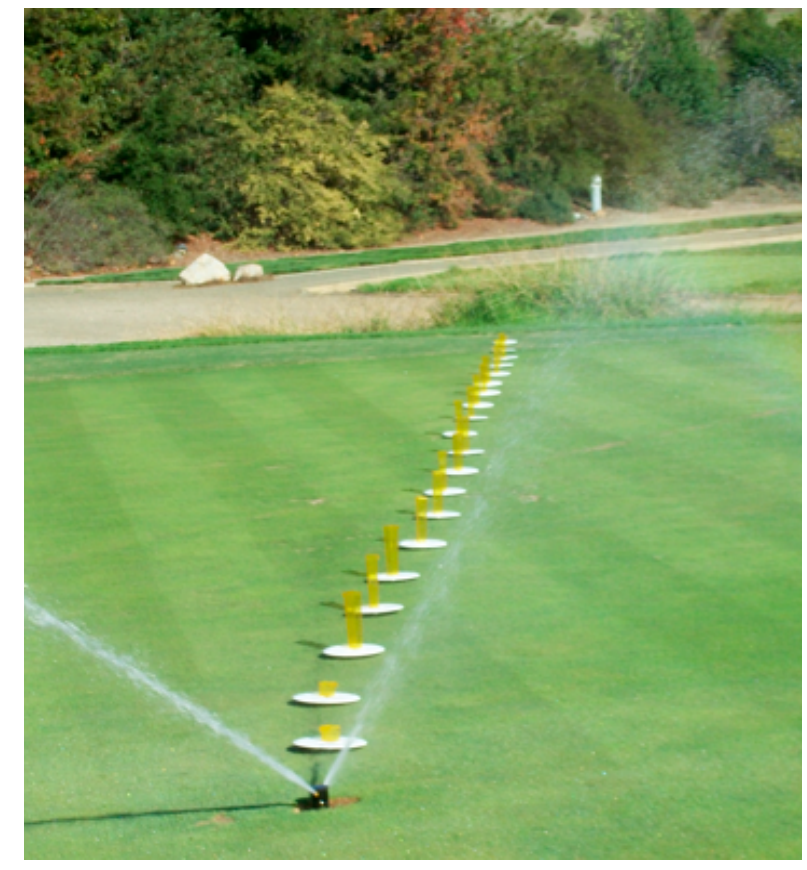

Figure 1. Irrigation audit

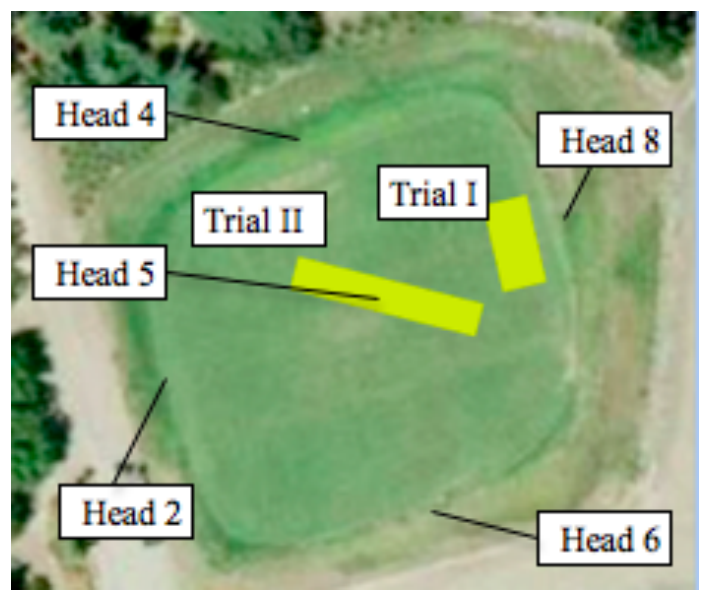

Figure 2. Irrigation heads in relation to the green 


\section{CHAPTER 4}

\section{RESULTS AND DISCUSSION}

\section{Soil Analysis and Volumetric Water Content (VWC) Range}

The soil analysis on the $12 \mathrm{~cm}$ cores revealed that soil $\mathrm{pH}$ was slightly higher and that macronutrients were lower in an area showing hydrophobic localized dry spots (LDS) than over the entire green (Figure 3 and Appendix B). The organic matter content of the hydrophobic area $(0.8 \%)$ was less than the entire green $(1.4 \%)$. However, both areas were lower than the maximum organic matter content of 3 percent recommended by O’Brien and Hartwiger (2003).

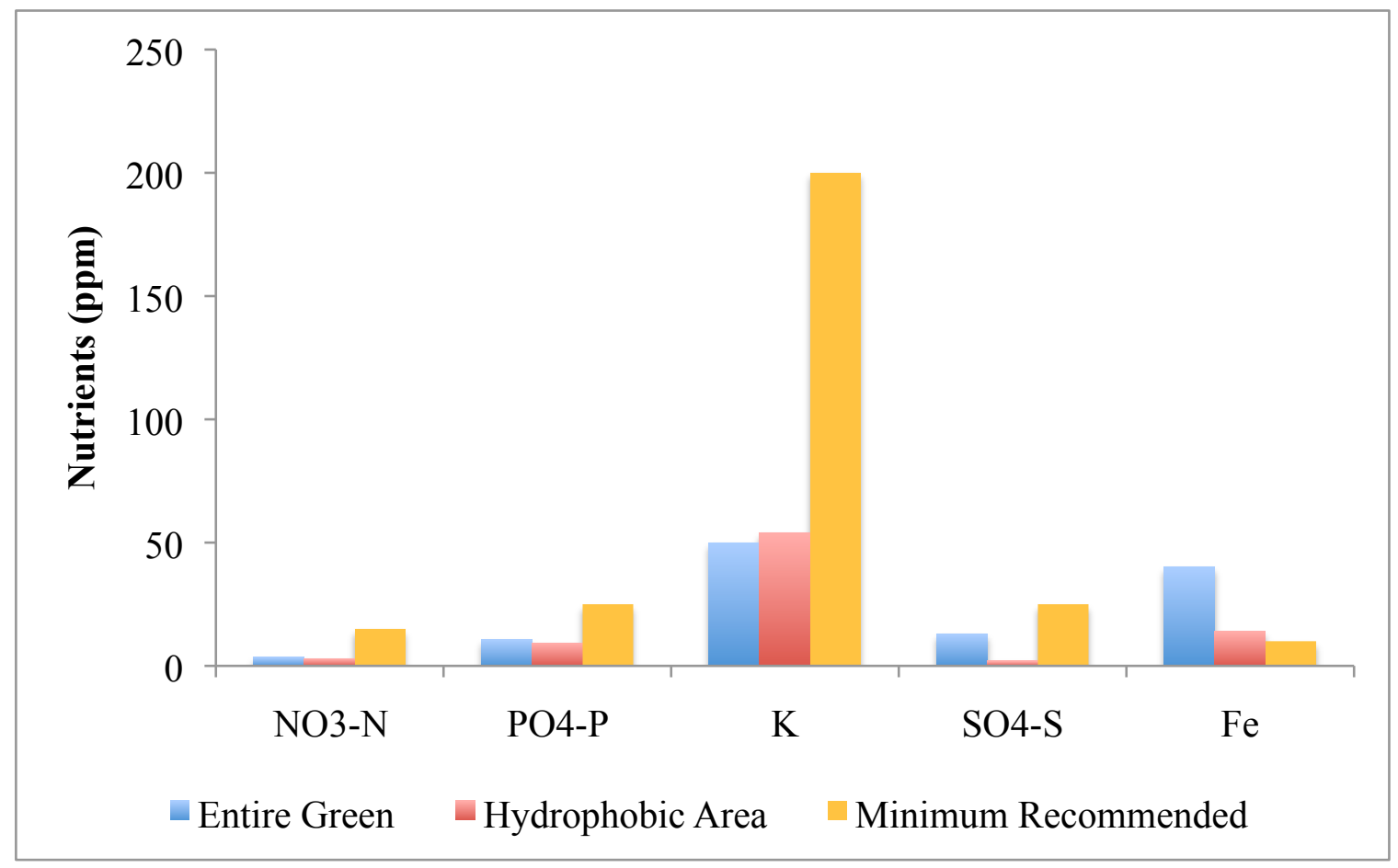

Figure 3. Soil analysis in the surface $12 \mathrm{~cm}$ of the green root zone. 
Volumetric water content (VWC) in relation to water tension is expressed in a soil moisture characteristic (SMC) curve (Figure 4). The correct irrigation interval range for irrigation is midpoint field capacity and permanent wilting point prior to irrigation and field capacity after irrigation. The VWC associated with saturation, field capacity, and permanent wilting point was found to be 54.2 percent, 15.4 percent, and 4.4 percent respectively for the uppermost $3 \mathrm{~cm}$. The VWC associated with saturation, permanent wilting point and field capacity for 3 to $6 \mathrm{~cm}$ was found to be 43.2 percent, 5.8 percent, and 10.3 percent respectively. Available water holding capacity (AWHC) for the top 3 $\mathrm{cm}$ (11 percent) was found to be much higher than the AWHC 3 to $6 \mathrm{~cm}$ deep (4 percent). This is not unusual as organic material builds up in the top $3 \mathrm{~cm}$ of green root zones (O'Brien and Hartwiger, 2003). The correct irrigation interval range for the surface $3 \mathrm{~cm}$ on the green used in this study was found to be between 15.4 and 9.9 percent VWC.

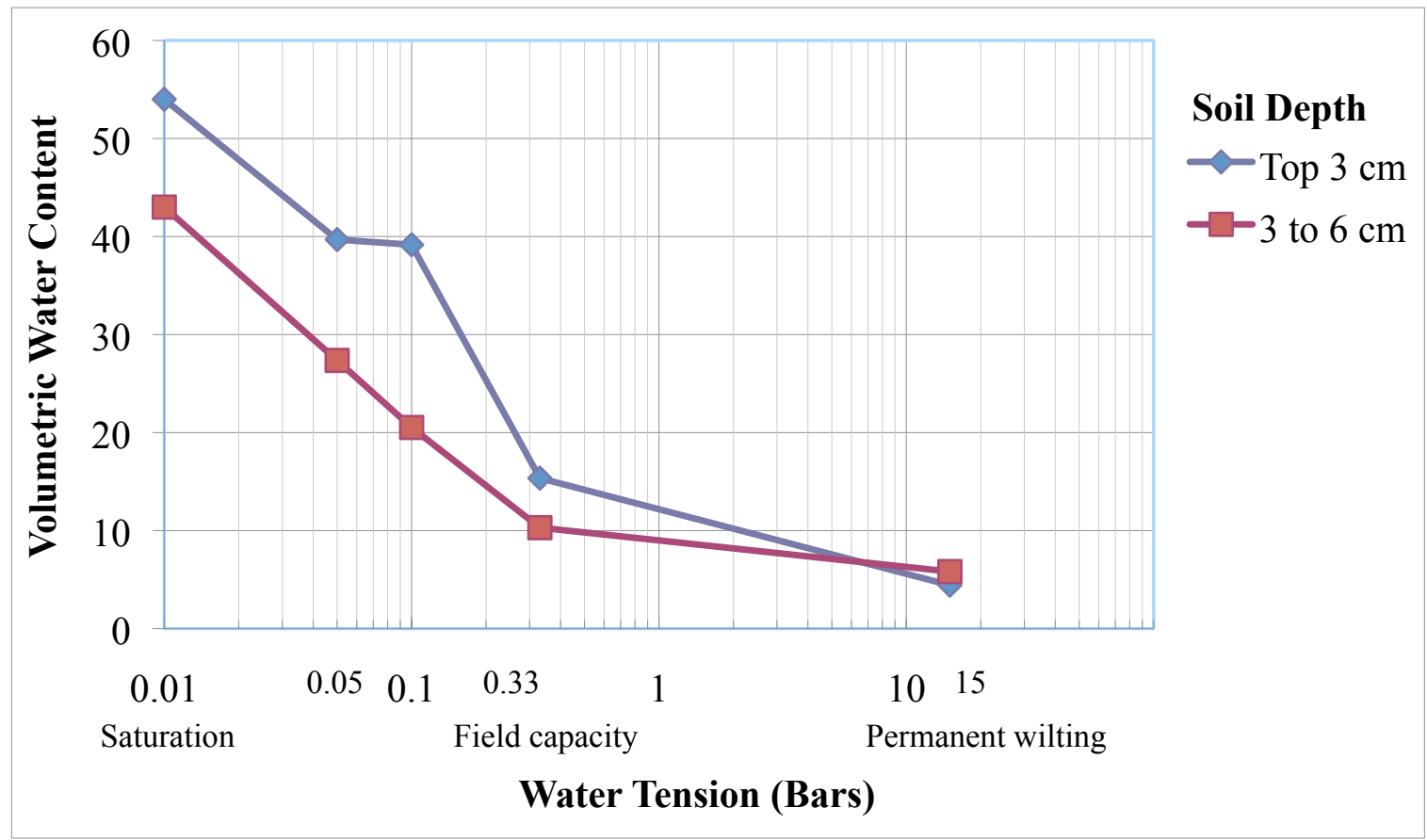

Figure 4. Soil moisture characteristic (SMC) curve. 


\section{Control Plots}

Soil hydrophobicity (all depths combined) for untreated control plots was higher during Trial II than during Trial I (Figure 5). Control soil hydrophobicity increased as maximum air temperature averaged 30 days prior to core extraction increased (20 to 26 ${ }^{\circ} \mathrm{C}$ ) for Trial I but not for Trial II. Control soil hydrophobicity started off lower for Trial I (22.8 seconds) than for Trial II (93.5 seconds) but gradually increased until reaching 100 seconds WDPT. Control soil hydrophobicity fluctuated around 125 seconds WDPT during the first three months of Trial II before declining.

The effect of temperature on soil hydrophobicity may be related to the initial level of soil hydrophobicity. Increased soil hydrophobicity at the beginning of the growing season may allow for less intensification as the growing season progresses.

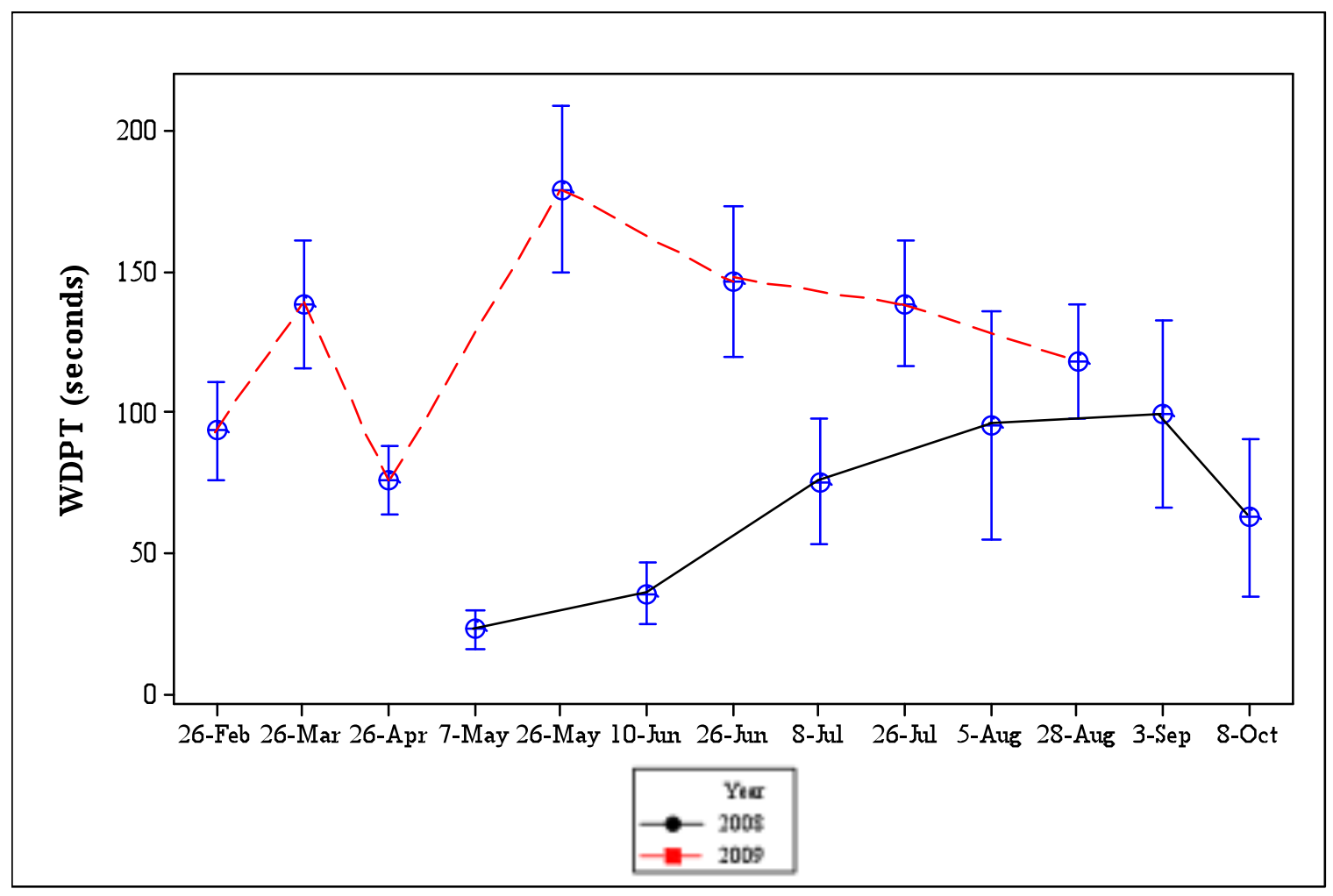

Figure 5. Soil hydrophobicity of untreated control plots during Trial I (2008) and during Trial II (2009). Error bars represent $95 \%$ confidence interval for the mean. 
High air temperature averaged one month prior to core extractions steadily climbed during both 2008 and during 2009 (Figure 6). High air temperatures for May of 2009 were greater than high air temperatures for May of 2008. High air temperatures for June of 2008 were greater than high air temperatures for June of 2009.

High air temperature, averaged 30 days prior to core extraction, was greater in August and September than during the other months during Trial I (Figure 6). During Trial II, high air temperature averaged 30-days prior to core extraction was highest during July and August (Figure 6).

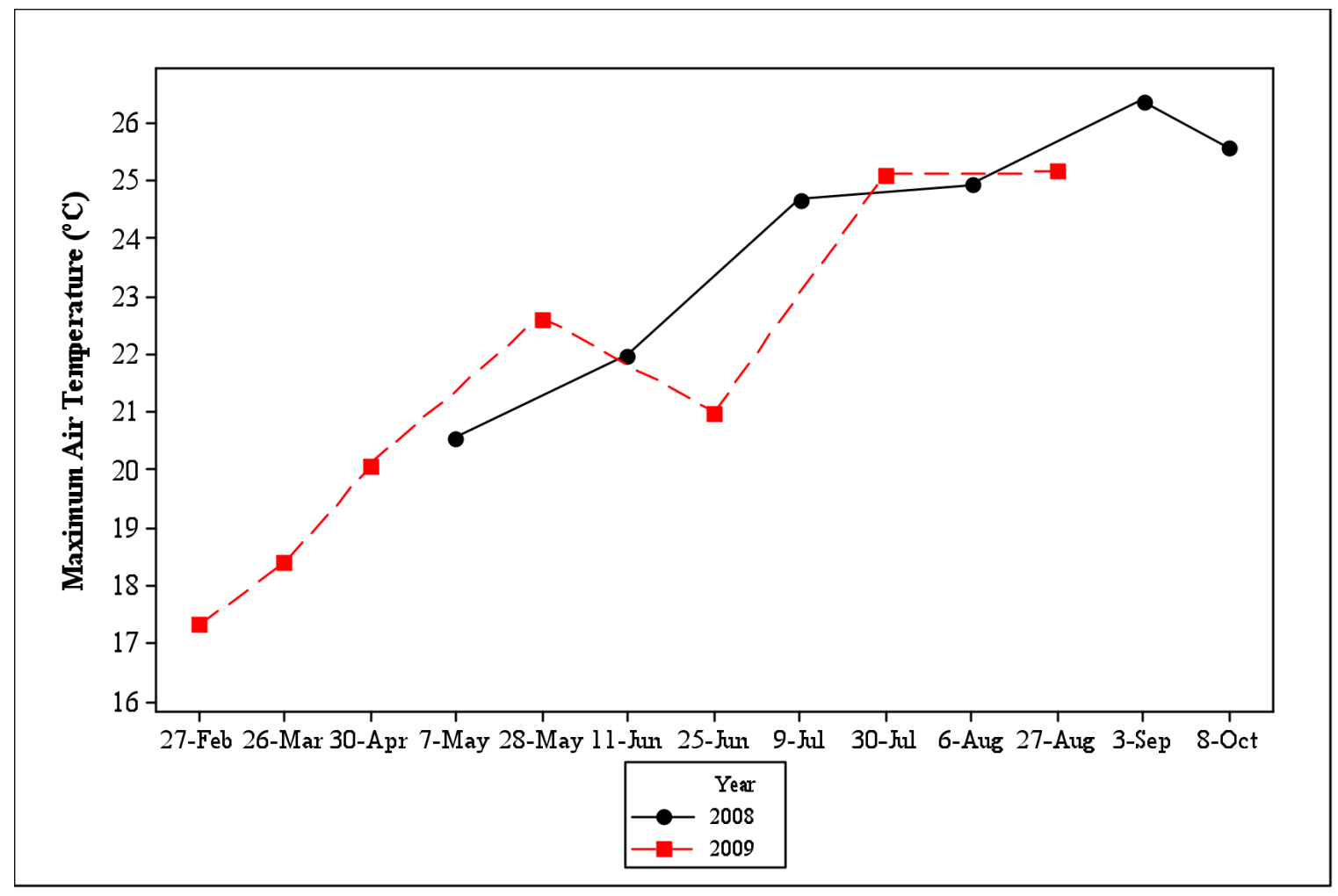

Figure 6. Maximum air temperature from CIMIS (averaged 30 days prior to core extraction) during Trial I (2008) and during Trial II (2009).

Control soil hydrophobicity in 2009 increased the most from April to May (Figure 5) during the same period when green root zone soil temperature increased the most 
(Figure 7). Fertilization of the green with $1 \mathrm{lb}$. N on 19 March 2009 may have stimulated the consumption of organic material by microorganisms and may have eventually decreased soil hydrophobicity in April. The application of granular surfactant to the entire green to help with fertilizer uptake may also have decreased control soil hydrophobicity in April.

No fairy ring symptoms were observed in the experimental area. In 2009, root zone soil temperature did not reach $37^{\circ} \mathrm{C}$ as recommended by Alexander (1977) for surface growing fungi (Figure 7). Soil temperature at $2 \mathrm{~cm}$ in depth stayed consistently warmer than for $10 \mathrm{~cm}$. This is not unusual as the soil at $10 \mathrm{~cm}$ is better insulated from solar heat than the soil at $2 \mathrm{~cm}$. On average the ambient temperature at the surface of the green stayed between soil temperature at $2 \mathrm{~cm}$ and soil temperature at $10 \mathrm{~cm}$.

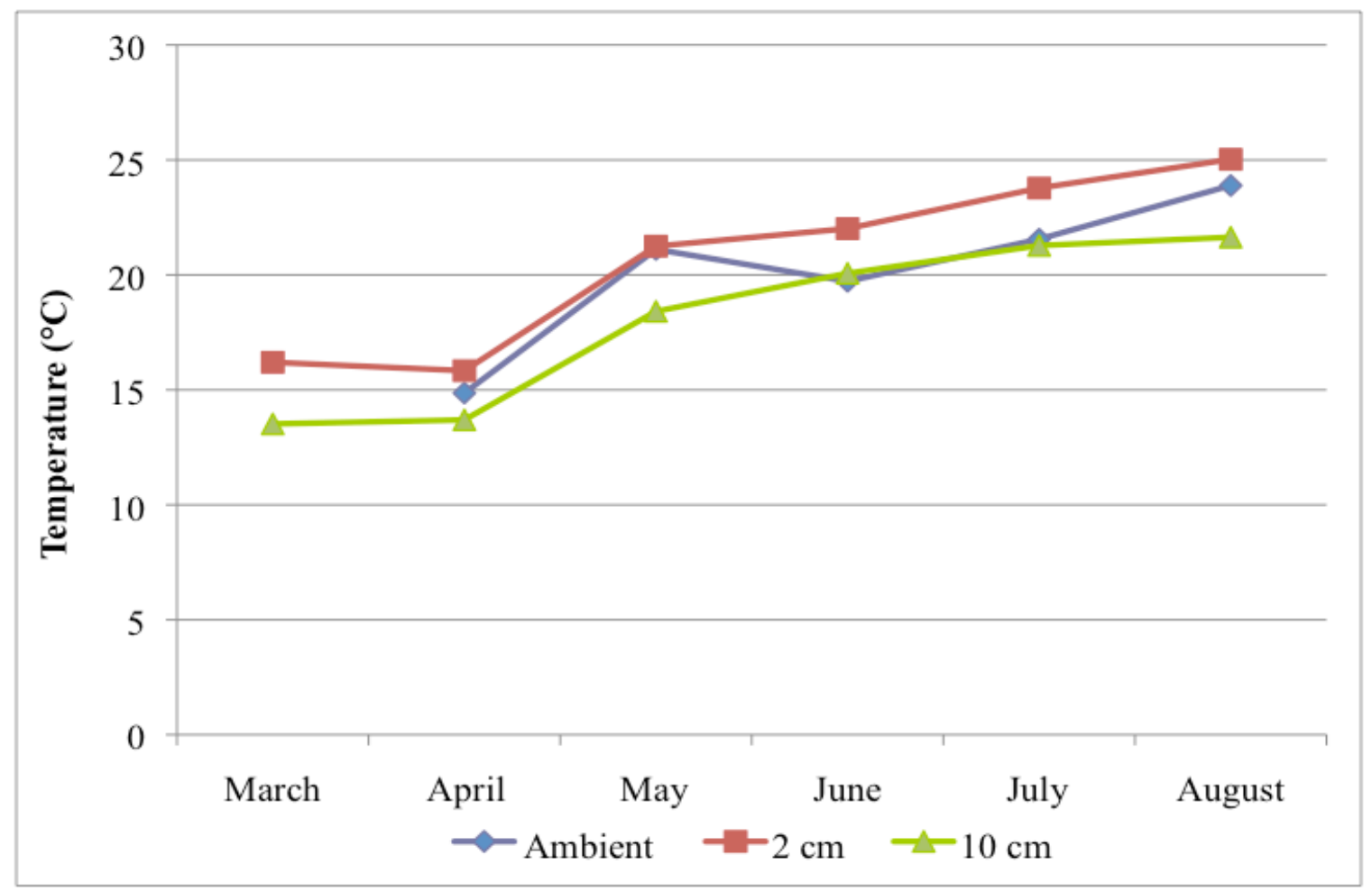

Figure 7. Green root zone soil temperature and surface ambient temperature obtained using a soil thermometer during Trial II (2009). 
Spot watering (hand watering) was applied during May through July to protect the green against heat stress and help minimize the intensification of soil hydrophobicity and formation of localized dry spots caused by soil dry down as described by Horne and McIntosh (2000). The wetting agent treated plots required little to no spot watering compared to the rest of the green.

Soil moisture was relatively uniform at 0 to $5.8 \mathrm{~cm}$ and at 5.8 to $12 \mathrm{~cm}$ depths during 2009 (Figure 8). With the exception of March, the month in which granular surfactants were applied for fertilizer uptake, soil moisture was less in the surface $5.8 \mathrm{~cm}$ and greater at 5.8 to $12 \mathrm{~cm}$.

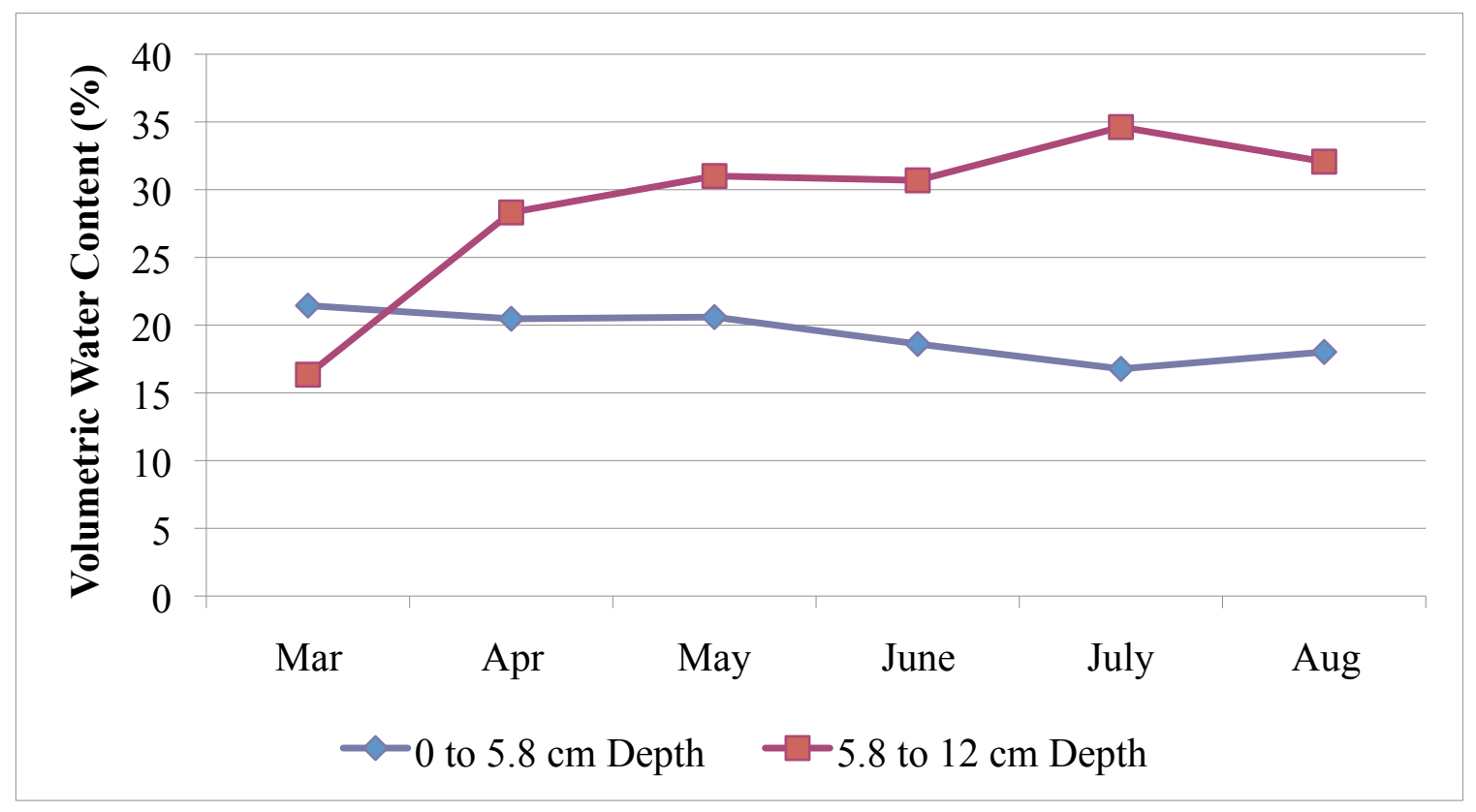

Figure 8. Volumetric water content (VWC) of untreated control plots obtained using a time domain reflectometer at 0 to $5.8 \mathrm{~cm}$ and $12 \mathrm{~cm}$ root zone depths.

Prolonged soil dry downs or periods between irrigation (mid-April and late-June of 2009) may have decreased the spread soil hydrophobicity by restoring healthy oxygen 
levels to the roots which may have also helped to prevent dead roots from clogging adjacent soil macropores (Carrow, 1996). It needs to be noted here that while soil dry downs may intensify actual soil hydrophobicity, WDPT readings for potential soil hydrophobicity are not affected by soil dry downs as all samples were tested after a soil dry down period of two weeks as stated earlier in the methods and materials section of this paper.

Evapotranspiration (ET) peaked in May through July during both years (Figure 9). ET for April was higher than for June during 2009. ET was greater and fluctuated less during 2008 than during 2009. Precipitation in the form of rainfall exceeded ET by approximately $100 \mathrm{~mm}$ during February.

ET increased (Figure 9) as maximum air temperature increased (Figure 6) from February to May of 2009. With the exception of April, soil hydrophobicity also increased from February to May of 2009 (Figure 5). After May of 2009 ET fluctuated as maximum air temperature increased and soil hydrophobicity decreased. With the exception of March through April of 2009, trends in soil hydrophobicity appeared to be related to ET during both years. 


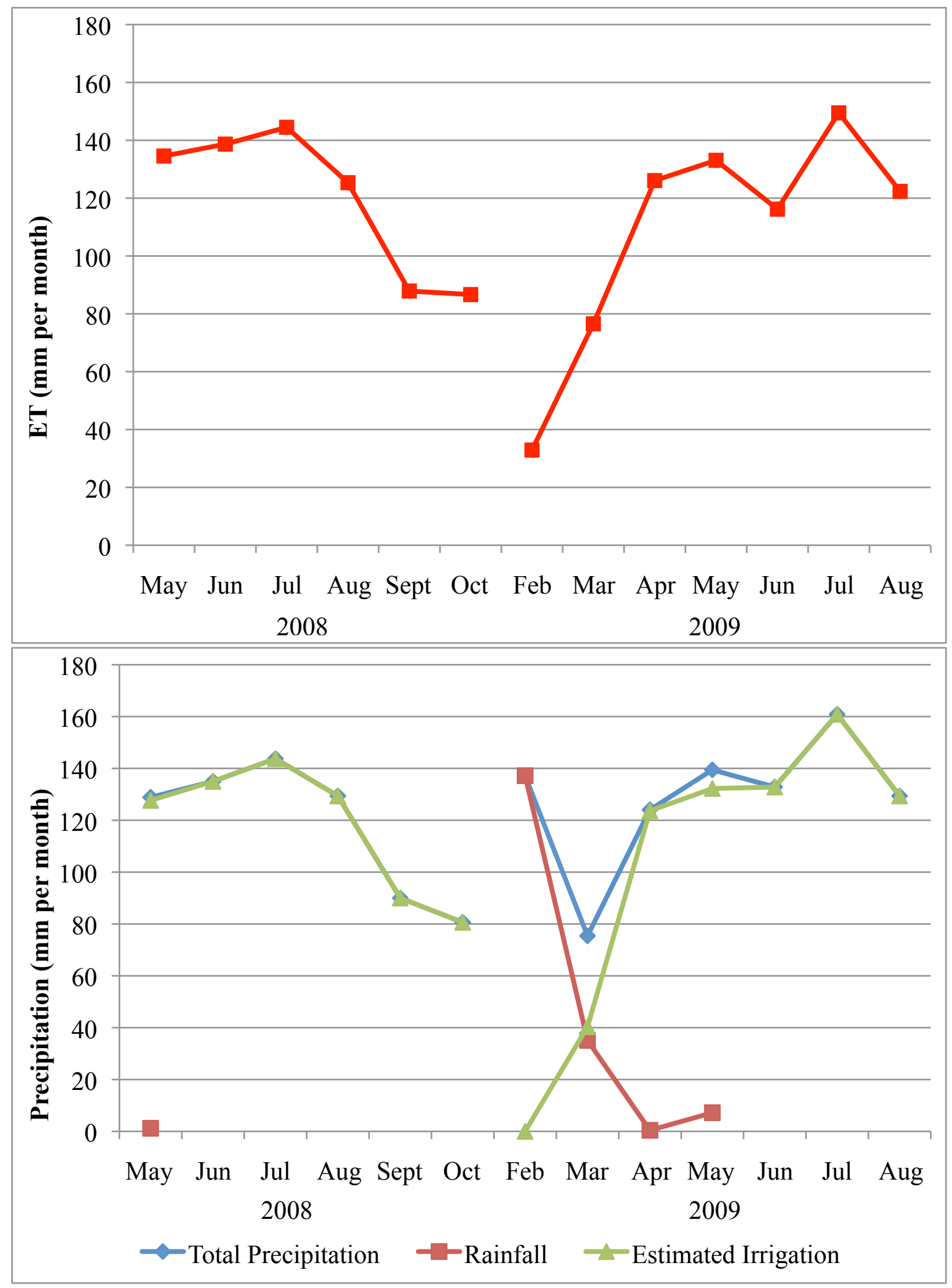

Figure 9. Evapotranspiration (ET) requirements of the green and estimated precipitation including rainfall during Trial II (2009) calculated using CIMIS data. 
There was a significant $(\mathrm{p} \leq 0.001)$ correlation of humidity and soil hydrophobicity during 2008 (Figure 10). For every one unit increase in relative humidity the log of soil hydrophobicity is predicted to increase by 5 percent. However, there was no significant ( $\mathrm{p} \geq 0.884$ ) effect of humidity on soil hydrophobicity during 2009 (Appendix C).

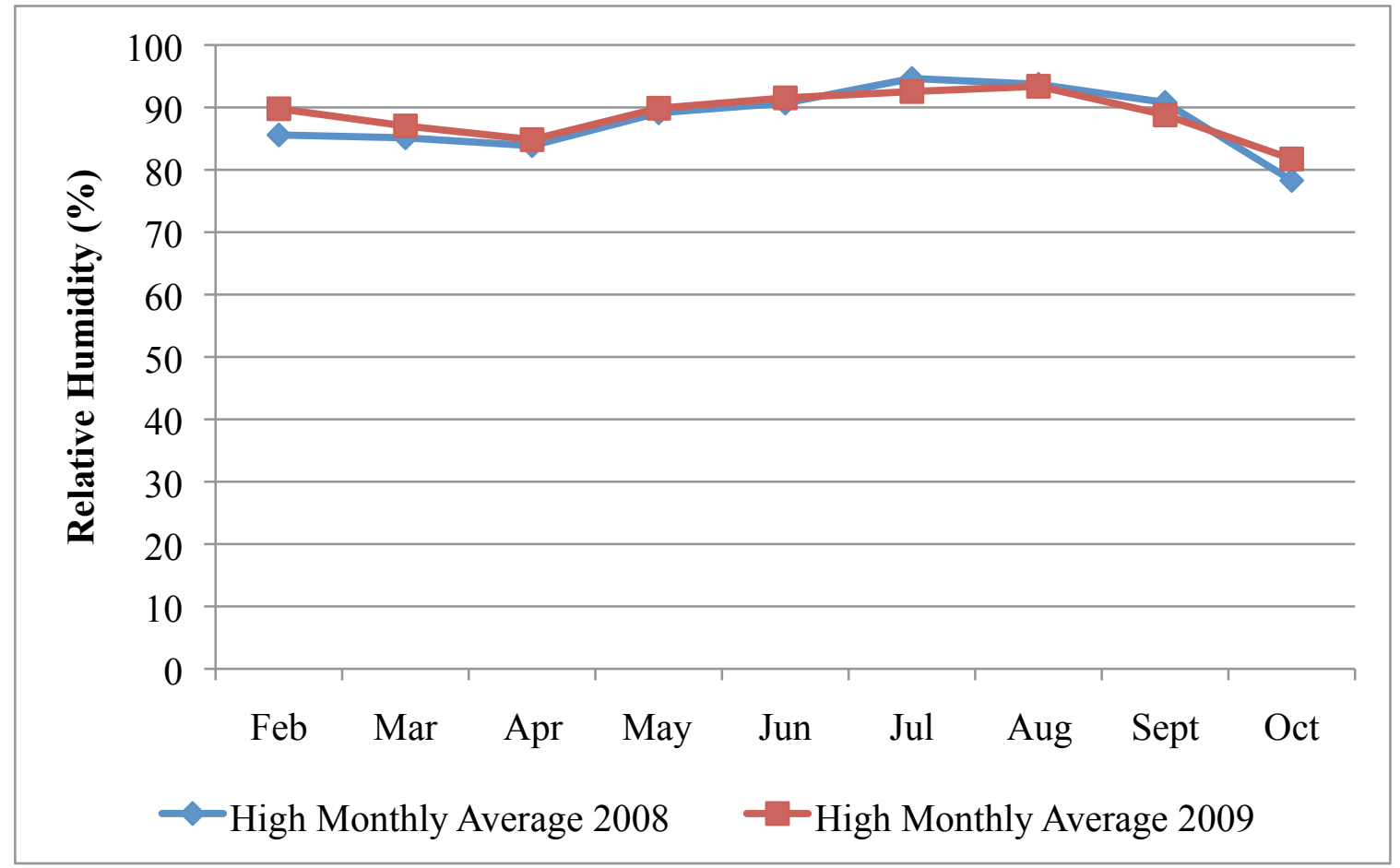

Figure 10. Maximum relative humidity from CIMIS during Trial I (2008) and Trial II (2009).

It is possible that soil hydrophobicity as caused by humidity may be limited to a certain minimum value and duration. Humidity values during 2009 may not have been high enough or long enough in duration to sufficiently stimulate hydrophobic producing organisms in the rootzone of the green (Jaramillo, et al., 2000). 


\section{Effect of Wetting Agent Treatments on Soil Hydrophobicity}

Overall soil hydrophobicity, as measured using the water droplet penetration time (WDPT) test, was greater in 2009 than in 2008 (Table 3). During both years, the cores from plots treated with surfactants 1-ACA 1820 and 2-ACA 2787 had a significantly $(\mathrm{p}<$ 0.05) shorter WDPT (water droplet penetration time) than 3-ACA 2892, 4-ACA 2983, 5ACA 1848 and the control. Wetting agents 1-ACA 1820 and 2-ACA 2787 did not differ significantly $(\mathrm{p}<0.05)$ in WDPT from each other.

It is difficult to tell the reason why treatments 1-ACA 1820 and 2-ACA 2787 performed better than treatments 3-ACA 2892, 4-ACA 2893, and 5-ACA 1848. One may wish to increase the application rates of wetting agent treatments 3-ACA 2892, 4-ACA 2893, and 5-ACA 1848 to match that of 1-ACA 1820 and 2-ACA 2787 to see if the reason these treatments performed poorly was due to a lower application rate.

Table 3. WDPT(seconds) of Aquatrols wetting agent treatments during Trial I (2008) and Trial II (2009)

\begin{tabular}{|c|c|c|c|c|c|}
\hline Trial I & Treatment & Mean & Trial II & Treatment & Mean \\
\hline & 1-ACA 1820 & $35.04 \mathrm{a}$ & & 1-ACA 1820 & $62.9 \mathrm{a}$ \\
\hline & 2-ACA 2787 & $35.46 \mathrm{a}$ & & 2-ACA 2787 & $71.8 \mathrm{a}$ \\
\hline & 3-ACA 2892 & $62.36 \mathrm{~b}$ & & 3-ACA 2892 & $137.6 \mathrm{~b}$ \\
\hline & 4-ACA 2893 & $72.57 b$ & & 4-ACA 2893 & $123.2 \mathrm{~b}$ \\
\hline & 5-ACA 1848 & $66.08 \mathrm{~b}$ & & 5-ACA 1848 & $130.1 b$ \\
\hline & 6-Control & $65.24 b$ & & 14-Control & $127.4 \mathrm{~b}$ \\
\hline
\end{tabular}

${ }^{\mathrm{a}}$ Means with the same letter are not significantly different according to the Tukey Method (Appendix C).

Wetting agent treatments 1-ACA 1820 and 2-ACA 2787 performed competitively throughout 2008 (Figure 11). Half of the time 1-ACA 1820 reduced WDPT the most and half of the time 2-ACA 2787 reduced WDPT the most.

From June to July all but two treatments (2-ACA 2787 and 5-ACA 1848) significantly increased in soil hydrophobicity. When soil hydrophobicity peaked from 6 
August 2008 until 3 September 2008, 1-ACA 1820 reduced soil hydrophobicity more than 2-ACA 2787.

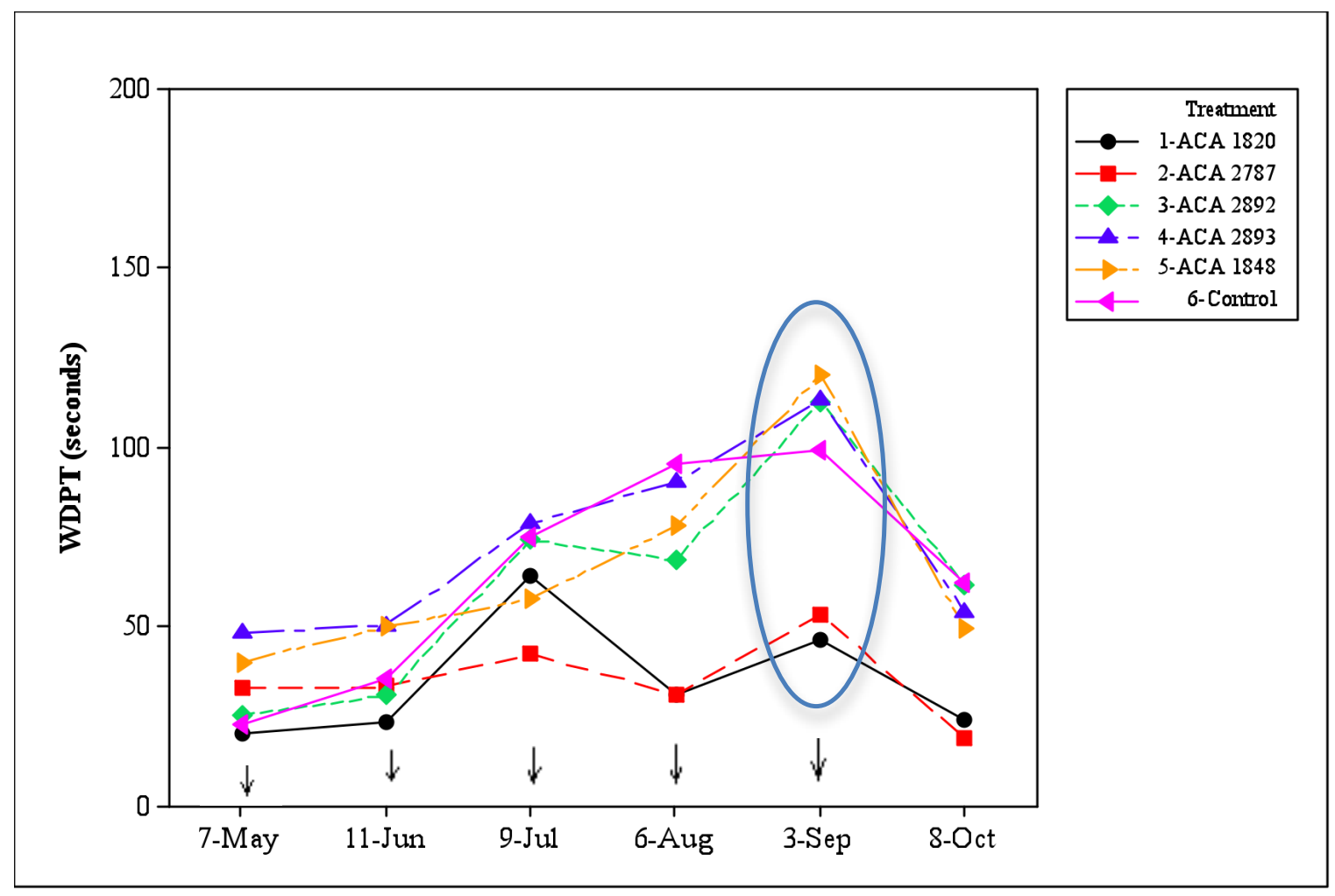

Figure 11. Water droplet penetration time (WDPT) of plots treated with Aquatrols (ACA) treatments during 2008. The five arrows indicate the five wetting agent application dates.

In August of both years, similar control soil hydrophobicity (Figure 5) and similar high air temperature (Figure 6) may have also caused the spread and order of performance of treatments during August of 2008 (Figure 11) to appear very similar to the spread and order of performance of wetting agent treatments during August of 2009 (Figure 12). Despite these similarities however, WDPT values were higher in August of 2009 (Figure 12) than during August of 2008 (Figure 11) though not significantly higher. 
Wetting agent treatment 3-ACA 2892 was the only treatment that significantly increased WDPT from May to June. Wetting agent treatment 3-ACA 2892 also delayed the reduction of soil hydrophobicity by two months at the beginning of the experiment and suggests that wetting agent 3-ACA 2892 may be delayed in its effectiveness.

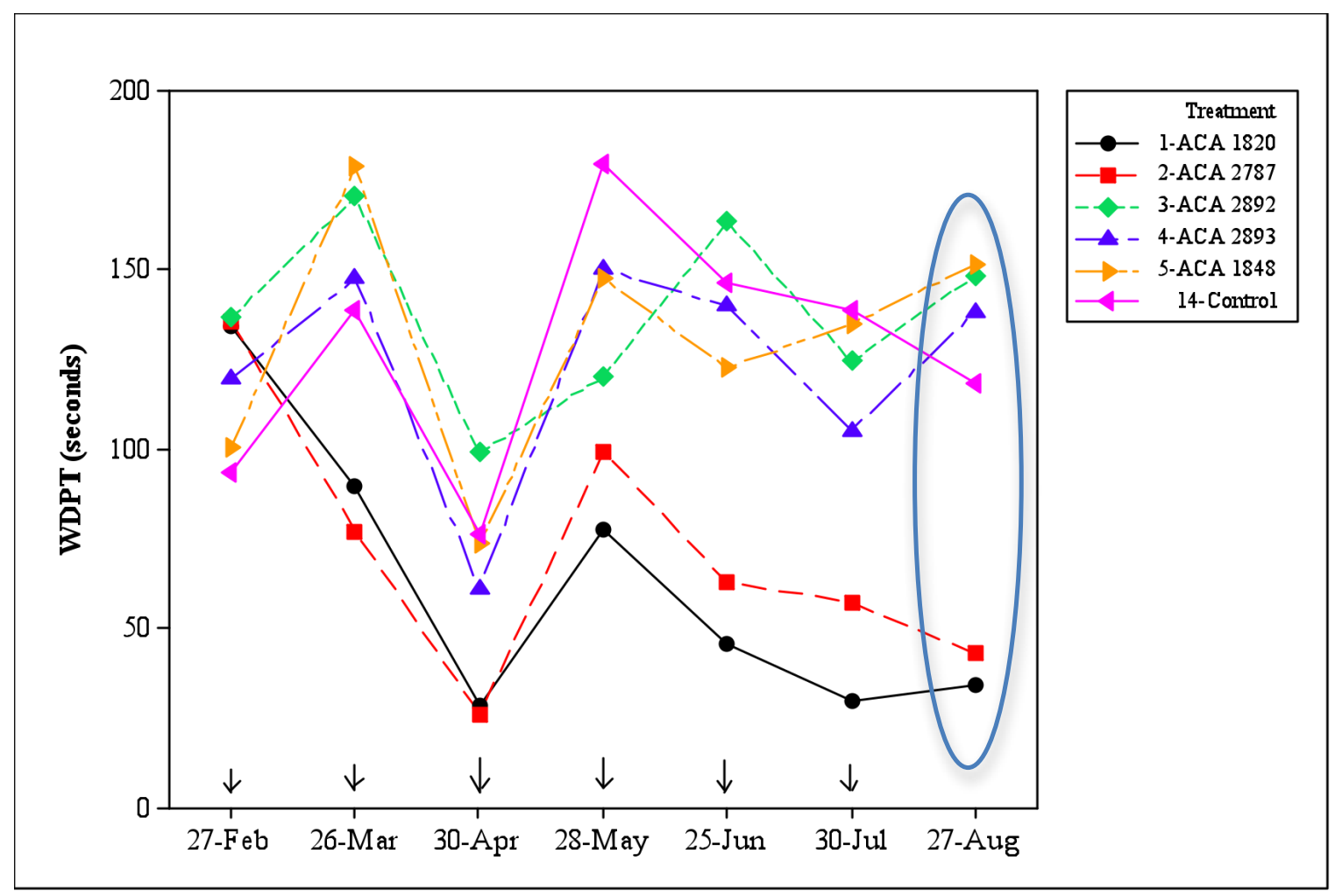

Figure 12. Water droplet penetration time (WDPT) of plots treated with Aquatrols treatments (ACA) during 2009. The six arrows indicate the six wetting agent application dates.

The effect of month on treatment WDPT was analyzed within a general linear model (Appendix C). At or near the end of Trial I (2008), treatments 1-ACA 1820 and 2ACA 2787 significantly reduced WDPT (Table 4). Also, the WDPT for untreated plots in 
May was significantly shorter $(\mathrm{p}<0.05)$ than for untreated plots in July, August, September, and October.

Table 4. WDPT(seconds) compared by month during Trial I (2008) ${ }^{\mathrm{a}}$

\begin{tabular}{l|cccccc}
\hline Treatment & May & June & July & August & September & October \\
\hline 1-ACA 1820 & $20.2 \mathrm{a}$ & $23.4 \mathrm{a}$ & $64.5 \mathrm{a}$ & $31.3 \mathrm{a}$ & $46.6 \mathrm{a}$ & $24.3 \mathrm{a}$ \\
2-ACA 2787 & $33 \mathrm{a}$ & $33.5 \mathrm{a}$ & $42.4 \mathrm{a}$ & $31.4 \mathrm{a}$ & $53.5 \mathrm{ab}$ & $19 \mathrm{a}$ \\
3-ACA 2892 & $25.5 \mathrm{a}$ & $30.9 \mathrm{a}$ & $74.4 \mathrm{a}$ & $68.3 \mathrm{a}$ & $113.1 \mathrm{~b}$ & $61.8 \mathrm{~b}$ \\
4-ACA 2893 & $48.4 \mathrm{a}$ & $50.6 \mathrm{a}$ & $78.4 \mathrm{a}$ & $90.6 \mathrm{a}$ & $113.3 \mathrm{ab}$ & $54.2 \mathrm{~b}$ \\
5-ACA 1848 & $40.4 \mathrm{a}$ & $50 \mathrm{a}$ & $57.9 \mathrm{a}$ & $78.1 \mathrm{a}$ & $120.1 \mathrm{ab}$ & $50 \mathrm{~b}$ \\
6-Control & $22.8 \mathrm{ax}$ & $35.6 \mathrm{axy}$ & $75.5 \mathrm{ay}$ & $95.7 \mathrm{ay}$ & $99.4 \mathrm{aby}$ & $62.5 \mathrm{by}$ \\
\hline
\end{tabular}

${ }^{a}$ Means with the same letter within a column (a-b) or row (x-y) are not significantly different from each other using a GLM (General Linear Model) and Tukey pairwise comparison test (Appendix C); $\alpha$ $($ significance level $)=0.05$.

From shortest to longest WDPT, wetting agent treatments performed in the following order during Trial II: 6-Cascade Plus (10day), 7-Cascade Plus (60 day), 112079336 (8ml), 1-ACA 1820, 10-2079336 (5ml), 12-2079337 (5ml), 2-ACA 2787, 13 2079337 (8ml), 8-Magnus, 9-Magnus+Duplex, 4-ACA 2893, the control, 5-ACA 1848, and 3-ACA 2892, respectively (Figure 13). Diversity in performance among the surfactants occurred when the high temperature increased from 19.9 degrees Celsius in April to 22.3 degrees Celsius in May (Figure 13). This is not unusual as soil hydrophobicity can intensify with warm temperature (Carrow, 1996) and (Franco et al., 2000).

\section{Application Frequency}

Increasing the application frequency also reduced WDPT (Appendix D). Cascade Plus treated every ten days performed significantly $(\mathrm{p}<0.001)$ better in reducing WDPT than Cascade Plus treated every 60 days (Figure 13). This is not surprising as a similar conclusion was also reached by Miller (2001). 


\section{Application Rate (Amount)}

Increasing application rate also reduced soil hydrophobicity (WDPT). Increasing the application rate of 2079336 from $5 \mathrm{ml}$ per $110 \mathrm{ml}$ to $8 \mathrm{ml}$ per $110 \mathrm{ml}$ significantly (p $<0.002$ ) reduced WDPT (Figure 13). Increasing the application rate of 2079337 from 5 $\mathrm{ml}$ to $8 \mathrm{ml}$ reduced WDPT but not significantly (Appendix D).

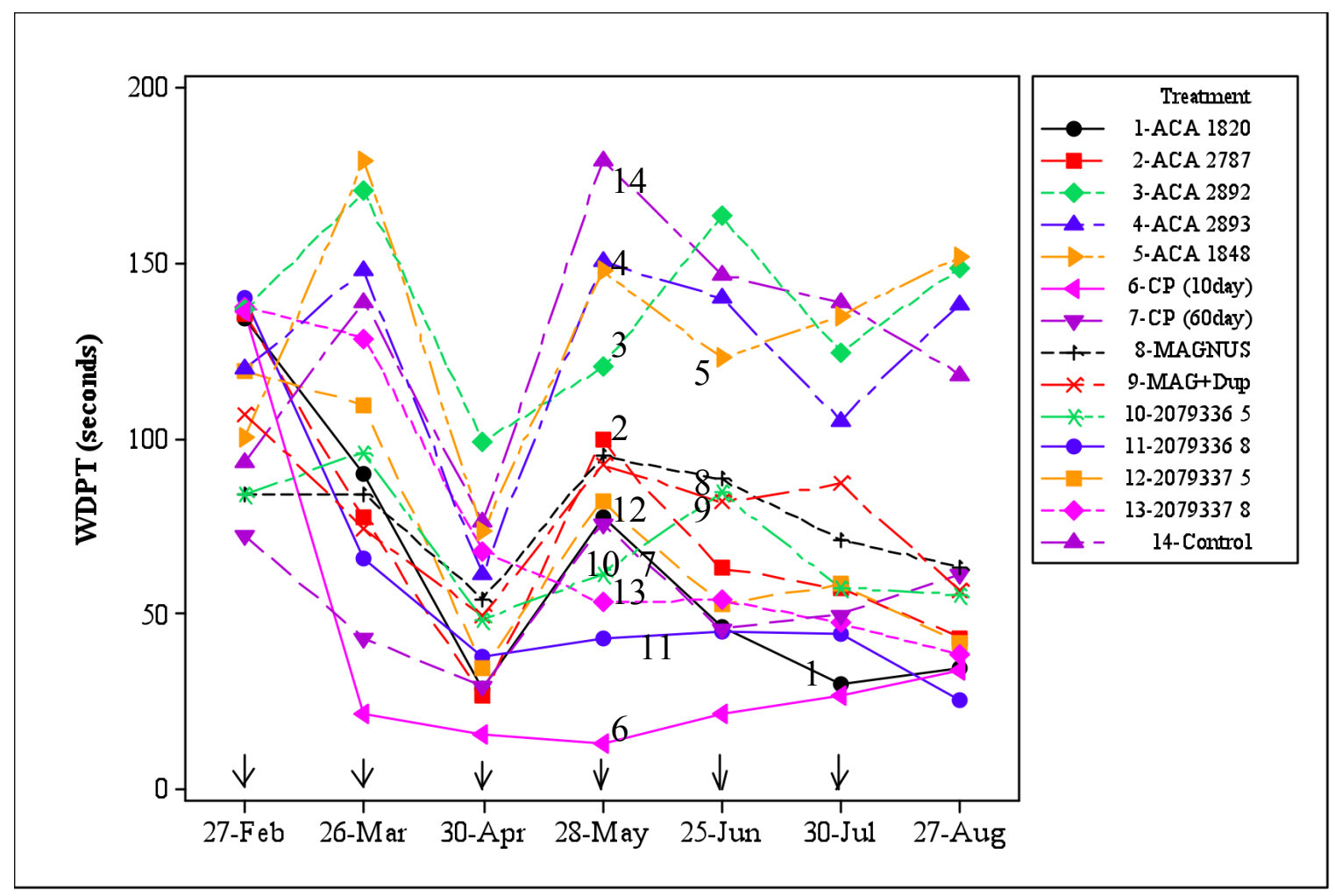

Figure 13. Water droplet penetration time (WDPT) of treated and untreated plots during 2009. Treatment application dates are indicated by arrows. The exception being 6$\mathrm{CP}(10$ day) and 7-CP(60day) which were applied every 10 days and every 60 days respectively.

From the ANOVA table (Appendix D) the p-was calculated to be less than 0.001 . Because the p-value was less than 0.05 , the null hypothesis is rejected. There is sufficient 
evidence to suggest a significant difference in penetration time among two or more of the wetting agent treatments.

Since there was a significant effect of treatment on soil hydrophobicity, a Tukey Kramer 95\% confidence interval using Minitab (Appendix D) was constructed to find which wetting agent treatments significantly decreased soil hydrophobicity. The WDPT for plots treated with 6-Cascade Plus every 10 days was significantly $(\mathrm{p}<0.001)$ shorter than the WDPT of all other treatments (Table 5). Next in line, 7-Cascade Plus treated every 60 days, 1-ACA 1820, and 11-2079336 (8ml) were not significantly $(\mathrm{p}>0.05)$ different from each other but performed significantly $(p<0.05)$ better in reducing soil hydrophobicity than 3-ACA 2892, 5-ACA 1848, 4-ACA 2893, 8-Magnus and 9Magnus+Duplex in that order. Treatments 10-2079336 (5ml), 12-2079337 (5ml), 2-ACA 2787, 13-2079337 (8ml), 8-Magnus and 9-Magnus +Duplex were not significantly (p > $0.05)$ different from each other but decreased penetration time significantly $(\mathrm{p}<0.05)$ compared with treatments 3-ACA 2892, 5-ACA 1848, 4-ACA 2893 and the control. Wetting agent treatments 3-ACA 2892, 5-ACA 1848, and 4-ACA 2893 did not differ significantly $(\mathrm{p}>0.05)$ in penetration time from the control.

Table 5. WDPT(seconds) during Trial II (2009)

\begin{tabular}{llll}
\hline Treatment & Mean & Treatment & Mean \\
\hline 1-ACA 1820 & $62.9 \mathrm{~b}$ & 8 -MAGNUS & $77.1 \mathrm{c}$ \\
2-ACA 2787 & $71.8 \mathrm{bc}$ & 9 -MAG+Duplex & $78.4 \mathrm{c}$ \\
3-ACA 2892 & $137.6 \mathrm{~d}$ & $10-2079336-5$ & $69.6 \mathrm{bc}$ \\
4-ACA 2893 & $123.2 \mathrm{~d}$ & $11-2079336-8$ & $57.3 \mathrm{~b}$ \\
5-ACA 1848 & $130.1 \mathrm{~d}$ & $12-2079337-5$ & $71.2 \mathrm{bc}$ \\
6-CP 10day & $38.3 \mathrm{a} *$ & $13-2079337-8$ & $75.3 \mathrm{bc}$ \\
7-CP 60day & $53.8 \mathrm{~b}$ & $14-$ Control & $127.4 \mathrm{~d}$ \\
\hline
\end{tabular}

${ }^{a}$ Means with the same letter are not significantly different according to Tukey's confidence interval. $\alpha<$ 0.05 . * represents $\alpha<0.001$ 
The effect of month on treatment WDPT was analyzed within a general linear model (Appendix D). Table 6 shows the number of times (months) each wetting agent performed better than the untreated control. Over half of the time, wetting agent treatments 6-CP (10day), 11-2079336-8, 7-CP (60day), and 1-ACA 1820 were better than the control. The other wetting agent treatments performed less favorably over half of the time than the control in minimizing soil hydrophobicity (Table 6).

Table 6. Comparison of wetting agents with control during Trial II (2009)

\begin{tabular}{|l|c|c|c|c|c|c|c|}
\hline Treatment & $\begin{array}{c}\text { Always } \\
\text { Worked }\end{array}$ & $\begin{array}{c}\text { Worked 5 } \\
\text { times }\end{array}$ & $\begin{array}{c}\text { Worked 4 } \\
\text { times }\end{array}$ & $\begin{array}{c}\text { Worked 3 } \\
\text { times }\end{array}$ & $\begin{array}{c}\text { Worked 2 } \\
\text { times }\end{array}$ & $\begin{array}{c}\text { Worked 1 } \\
\text { time }\end{array}$ & $\begin{array}{c}\text { Did not } \\
\text { Work }\end{array}$ \\
\hline 1-ACA 1820 & & & $\checkmark$ & & & & \\
\hline 2-ACA 2787 & & & & & $\checkmark$ & & \\
\hline 3-ACA 2892 & & & & & & & $\checkmark$ \\
\hline 4-ACA 2893 & & & & & & & $\checkmark$ \\
\hline 5-ACA 1848 & & & & & & & $\checkmark$ \\
\hline 6-CP (10day) & $\checkmark$ & & & & & & \\
\hline 7-CP (60day) & & & $\checkmark$ & & & & \\
\hline 8-MAGNUS & & & & & & $\checkmark$ & \\
\hline 9-MAG+Duplex & & & & & & $\checkmark$ \\
\hline 10-2079336-5 & & & & & & $\checkmark$ & \\
\hline 11-2079336-8 & & $\checkmark$ & & & & & \\
\hline 12-2079337-5 & & & & & $\checkmark$ & & \\
\hline $13-2079337-8$ & & & & & & $\checkmark$ & \\
\hline
\end{tabular}

\section{Depth and Movement of Wetting Agents}

Soil hydrophobicity was analyzed at different depths using the ANOVA and Tukey methods. During both years there was a significant interaction between treatments and depth in relation to penetration time (Figure 14). WDPT at $3 \mathrm{~cm}$ remained unusually longer than WDPT at $2 \mathrm{~cm}$ (Figure 14 and Figure 15). This is not unusual as surfactant adsorption near the surface reduces the amount of surfactant that is able to reach the greater depths. (Feng et al., 2002). 
The treatments used in 2008 were compared by depth (the distance from the grass surface on each core at which water droplets were placed). At greater than $3 \mathrm{~cm}$, treatment WDPT did not significantly differ from the control confirming that soil hydrophobicity is limited to the surface of green root zones (O'Brien and Hartwiger, 2003).

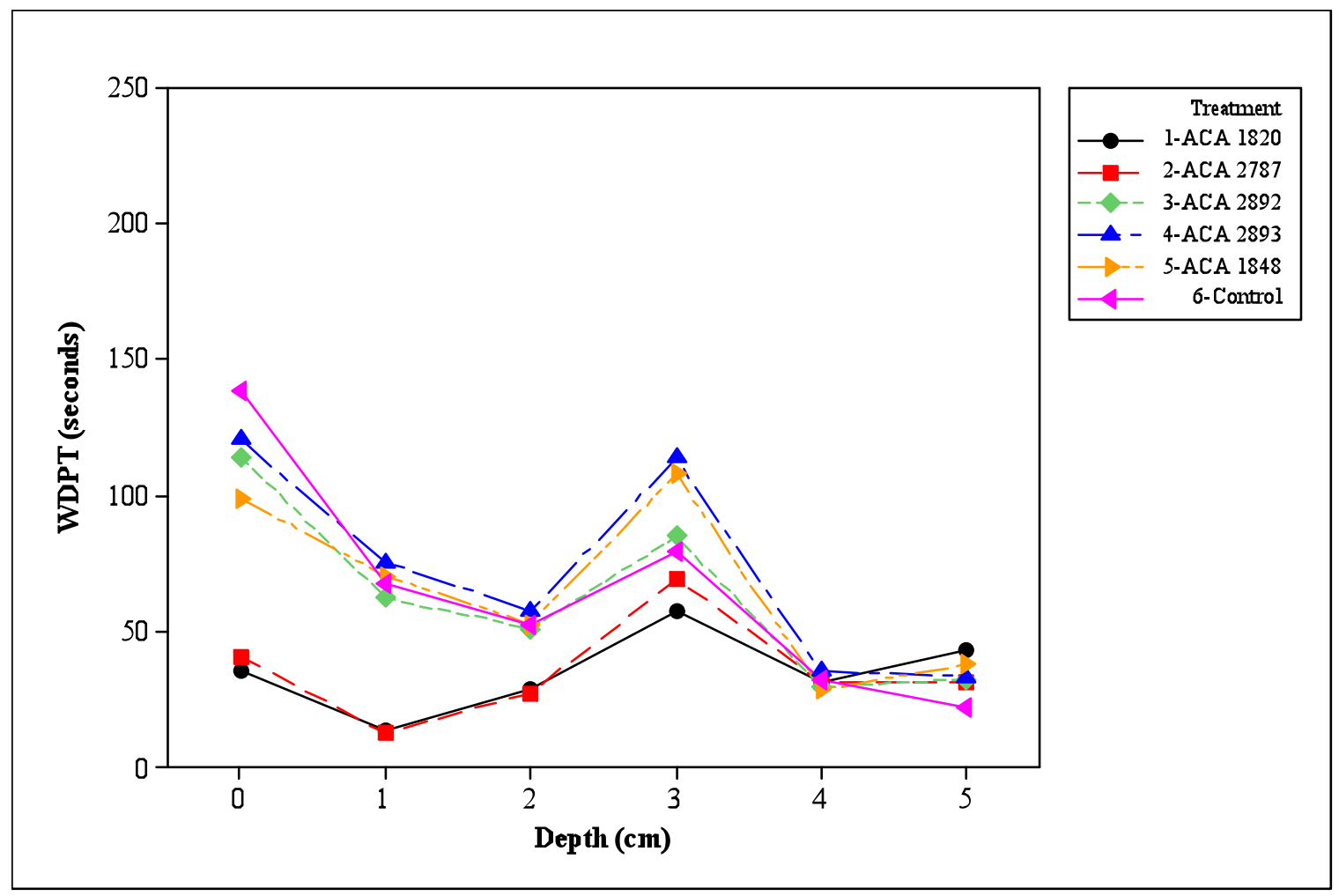

Figure 14. WDPT (seconds) for each depth (average of all dates) during Trial I (2008).

In the surface $2 \mathrm{~cm}$, wetting agent treatments 1-ACA 1820 and 2-ACA 2787 significantly $(\mathrm{p}<0.05)$ reduced WDPT compared with 3-ACA 2892, 4-ACA 2893, 5ACA 1848, and the control. (Table 7). 
At $3 \mathrm{~cm}$ deep, wetting agent treatment 1-ACA 1820 and the control significantly reduced WDPT compared with 4-ACA 2893 and 5-ACA 1848. No significance among treatments was detected deeper than $3 \mathrm{~cm}$.

Table 7. WDPT(seconds) compared by depth during Trial I (2008) ${ }^{\mathrm{a}}$

\begin{tabular}{l|cccccc}
\hline & \multicolumn{6}{|c}{ Soil Depth } \\
\cline { 2 - 7 } Treatment & $\mathbf{0 ~ c m}$ & $\mathbf{1 ~ c m}$ & $\mathbf{2 ~ c m}$ & $\mathbf{3 ~ c m}$ & $\mathbf{4} \mathbf{~ m}$ & $\mathbf{5 ~ c m}$ \\
\hline 1-ACA 1820 & $35.6 \mathrm{a}$ & $13.7 \mathrm{a}$ & $28.6 \mathrm{a}$ & $57.5 \mathrm{a}$ & $31.48 \mathrm{a}$ & $43.3 \mathrm{a}$ \\
2-ACA 2787 & $40.9 \mathrm{a}$ & $12.5 \mathrm{a}$ & $27.4 \mathrm{a}$ & $69.3 \mathrm{ab}$ & $31.3 \mathrm{a}$ & $31.6 \mathrm{a}$ \\
3-ACA 2892 & $114.3 \mathrm{~b}$ & $62.2 \mathrm{~b}$ & $51 \mathrm{~b}$ & $84.9 \mathrm{ab}$ & $29.6 \mathrm{a}$ & $32.3 \mathrm{a}$ \\
4-ACA 2893 & $121.4 \mathrm{~b}$ & $75.2 \mathrm{~b}$ & $57.7 \mathrm{~b}$ & $113.7 \mathrm{~b}$ & $35.2 \mathrm{a}$ & $33.2 \mathrm{a}$ \\
5-ACA 1848 & $99.2 \mathrm{~b}$ & $70.4 \mathrm{~b}$ & $52.8 \mathrm{~b}$ & $107.8 \mathrm{~b}$ & $28.5 \mathrm{a}$ & $37.8 \mathrm{a}$ \\
6-Control & $138.1 \mathrm{~b}$ & $67.5 \mathrm{~b}$ & $52 \mathrm{~b}$ & $79.7 \mathrm{a}$ & $32.3 \mathrm{a}$ & $21.9 \mathrm{a}$ \\
\hline
\end{tabular}

${ }^{a}$ Means with the same letter within a column are not significantly different from each other using a GLM (General Linear Model) and Tukey pairwise comparison test (Appendix C); $\alpha($ significance level $)=0.05$

Soil hydrophobicity was also analyzed at different depths among the treatments used in 2009 (Figure 15). There was a significant interaction between treatment and depth in relation to penetration time.

At an additional depth $(6 \mathrm{~cm})$ there was found to be virtually no difference in WDPT between treated and untreated control plots. At the surface, 1-ACA 1820 performed better in reducing soil hydrophobicity than 2-ACA 2787 during 2008 but performed worse than 2-ACA 2787 during 2009. These differences were not significant however. 


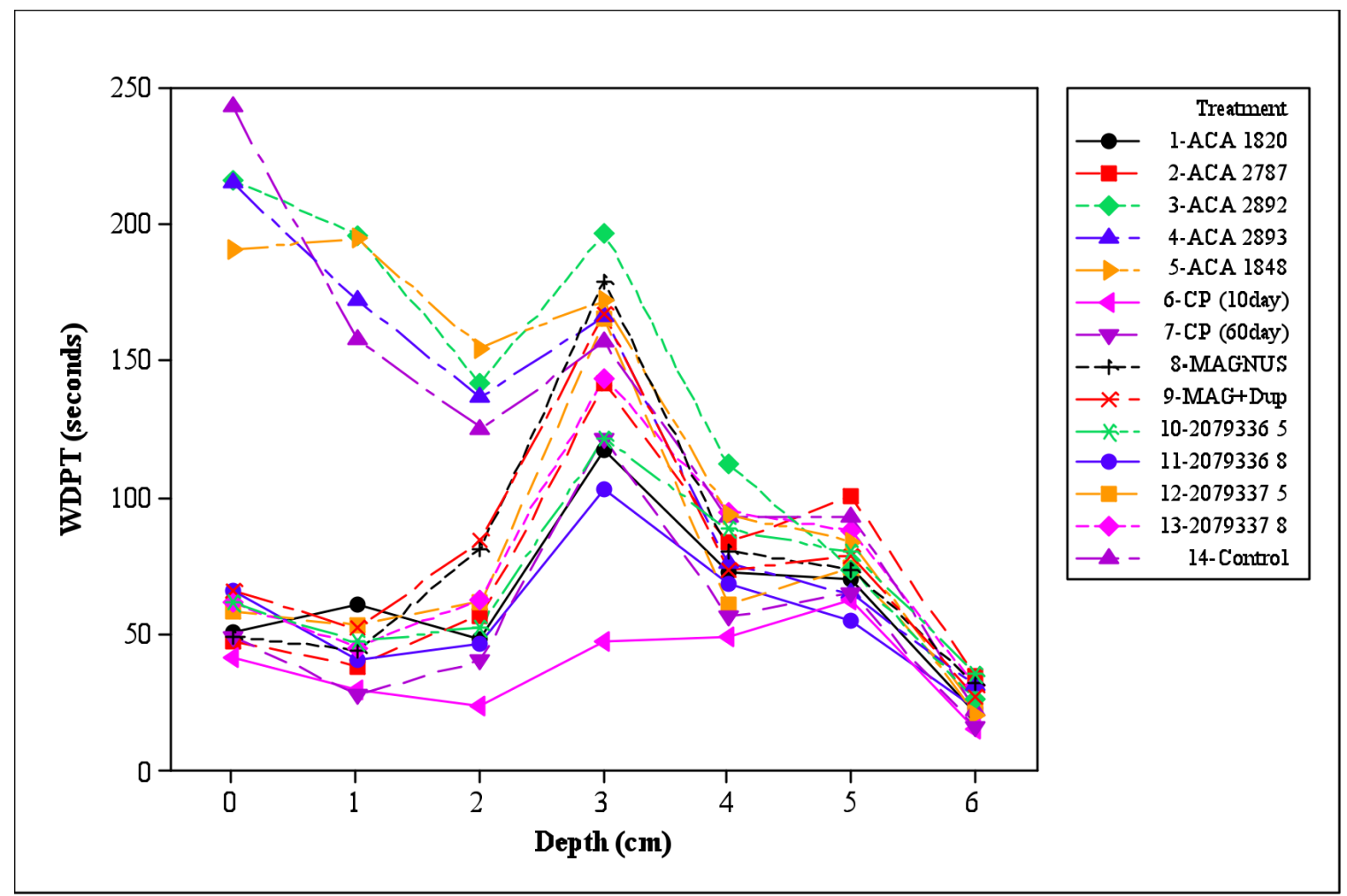

Figure 15. WDPT (seconds) for each depth (average of all dates) during Trial II (2009).

In the surface $2 \mathrm{~cm}, 3-\mathrm{ACA} 2892$, 4-ACA 2893, 5-ACA 1848, and the control had significantly $(\mathrm{p}<0.05)$ longer penetration times compared with 1-ACA 1820, 2-ACA 2787, 6-CP (10day), 7-CP (60day), 10-2079336 (5ml), 11-2079336 (8ml), 12-2079337 (5ml), and 13-2079337 (8ml) (Table 8). No significance was detected at greater than 4 cm confirming that soil hydrophobicity is limited to the upper 2.5 to $5 \mathrm{~cm}$ (Karnok and Tucker, 2002). 
Table 8. WDPT(seconds) compared by depth during Trial II (2009)

\begin{tabular}{l|ccccccc}
\hline & \multicolumn{7}{c}{ Soil Depth } \\
\cline { 2 - 8 } Treatment & $\mathbf{0 ~ c m}$ & $\mathbf{1 ~ c m}$ & $\mathbf{2 ~ c m}$ & $\mathbf{3} \mathbf{~ c m}$ & $\mathbf{4 ~ c m}$ & $\mathbf{5} \mathbf{~ c m}$ & $\mathbf{6 ~ c m}$ \\
\hline 1-ACA 1820 & $50.5 \mathrm{ab}$ & $60.4 \mathrm{ab}$ & $47.8 \mathrm{ab}$ & $117.3 \mathrm{bc}$ & $73 \mathrm{bc}$ & $69.7 \mathrm{a}$ & $21.4 \mathrm{a}$ \\
2-ACA 2787 & $47.5 \mathrm{ab}$ & $38.4 \mathrm{ab}$ & $56.7 \mathrm{~b}$ & $141.5 \mathrm{bc}$ & $83.3 \mathrm{bc}$ & $100.3 \mathrm{a}$ & $34.6 \mathrm{a}$ \\
3-ACA 2892 & $216.5 \mathrm{c}$ & $196.3 \mathrm{c}$ & $141.8 \mathrm{~d}$ & $197 \mathrm{c}$ & $112.2 \mathrm{c}$ & $73.7 \mathrm{a}$ & $25.8 \mathrm{a}$ \\
4-ACA 2893 & $215.2 \mathrm{c}$ & $172.5 \mathrm{c}$ & $137 \mathrm{~d}$ & $166.4 \mathrm{~b}$ & $75.7 \mathrm{ab}$ & $64.8 \mathrm{a}$ & $30.9 \mathrm{a}$ \\
5-ACA 1848 & $190.8 \mathrm{c}$ & $195.1 \mathrm{c}$ & $154.9 \mathrm{~d}$ & $172 \mathrm{bc}$ & $93.7 \mathrm{ab}$ & $84 \mathrm{a}$ & $20.1 \mathrm{a}$ \\
6-CP(10day) & $41.2 \mathrm{a}$ & $29.3 \mathrm{a}$ & $23.6 \mathrm{a}$ & $47.4 \mathrm{a}$ & $48.8 \mathrm{a}$ & $62.6 \mathrm{a}$ & $15 \mathrm{a}$ \\
7-CP(60day) & $49.1 \mathrm{ab}$ & $27.9 \mathrm{ab}$ & $40.2 \mathrm{~b}$ & $121.9 \mathrm{bc}$ & $56.2 \mathrm{abc}$ & $65.1 \mathrm{a}$ & $16.3 \mathrm{a}$ \\
8-MAGNUS & $49.3 \mathrm{~b}$ & $43.8 \mathrm{~b}$ & $81.3 \mathrm{bd}$ & $179.3 \mathrm{bc}$ & $80.4 \mathrm{abc}$ & $73.8 \mathrm{a}$ & $31.7 \mathrm{a}$ \\
9-MAG+duplex & $66.1 \mathrm{~b}$ & $52 \mathrm{~b}$ & $84.2 \mathrm{bd}$ & $167.6 \mathrm{bc}$ & $73.4 \mathrm{abc}$ & $78.7 \mathrm{a}$ & $26.9 \mathrm{a}$ \\
10-2079336-5 & $61.6 \mathrm{~b}$ & $47.1 \mathrm{~b}$ & $52.6 \mathrm{~b}$ & $122 \mathrm{bc}$ & $88.6 \mathrm{ab}$ & $79.9 \mathrm{a}$ & $35.4 \mathrm{a}$ \\
11-2079336-8 & $65.8 \mathrm{~b}$ & $40.1 \mathrm{~b}$ & $46.5 \mathrm{ab}$ & $103.2 \mathrm{ab}$ & $68.4 \mathrm{abc}$ & $54.6 \mathrm{a}$ & $22.4 \mathrm{a}$ \\
12-2079337-5 & $57.9 \mathrm{~b}$ & $53.2 \mathrm{~b}$ & $61.7 \mathrm{bc}$ & $165.3 \mathrm{bc}$ & $61 \mathrm{abc}$ & $74.7 \mathrm{a}$ & $24.7 \mathrm{a}$ \\
13-2079337-8 & $61.5 \mathrm{~b}$ & $45.1 \mathrm{ab}$ & $62.8 \mathrm{~b}$ & $143.6 \mathrm{bc}$ & $95 \mathrm{abc}$ & $88 \mathrm{a}$ & $30.9 \mathrm{a}$ \\
14-Control & $242.9 \mathrm{c}$ & $158.3 \mathrm{c}$ & $125.3 \mathrm{~cd}$ & $156.9 \mathrm{bc}$ & $93 \mathrm{abc}$ & $93.1 \mathrm{a}$ & $22.2 \mathrm{a}$ \\
\hline
\end{tabular}

${ }^{a}$ Means with the same letter within a column are not significantly different from each other using a GLM (General Linear Model) and Tukey pairwise comparison test (Appendix D); $\alpha$ (significance level) $=0.05$.

The effect of wetting agent treatment at each depth is shown for each wetting agent treatment and the control (Figure 16). Control soil hydrophobicity (WDPT) increased significantly in the top $1 \mathrm{~cm}$ by July and at $3 \mathrm{~cm}$ by September. Despite the increase in soil hydrophobicity, wetting agent treatment 1-ACA 1820 did not show any significant increase in soil hydrophobicity (WDPT) at any one depth. Wetting agent treatment 2-ACA 2787 showed a significant increase in soil hydrophobicity at depth $5 \mathrm{~cm}$ from May to September. Wetting agent treatment 3-ACA 2892 showed a significant increase in soil hydrophobicity in the surface $1 \mathrm{~cm}$ from May to August, at $3 \mathrm{~cm}$ from June to September, at $4 \mathrm{~cm}$ from May to July, and at $5 \mathrm{~cm}$ from May to September. For wetting agent treatments 4-ACA 2893 and 5-ACA 1848, soil hydrophobicity increased significantly at the surface from May to September and June to August and at $1 \mathrm{~cm}$ from May to September. 
The effect of wetting agents on soil hydrophobicity (WDPT) in 2008 may appear minimal because soil hydrophobicity was minimal to start with. Wetting agents may also decrease infiltration in non-water repellent soil (Feng et al., 2002).
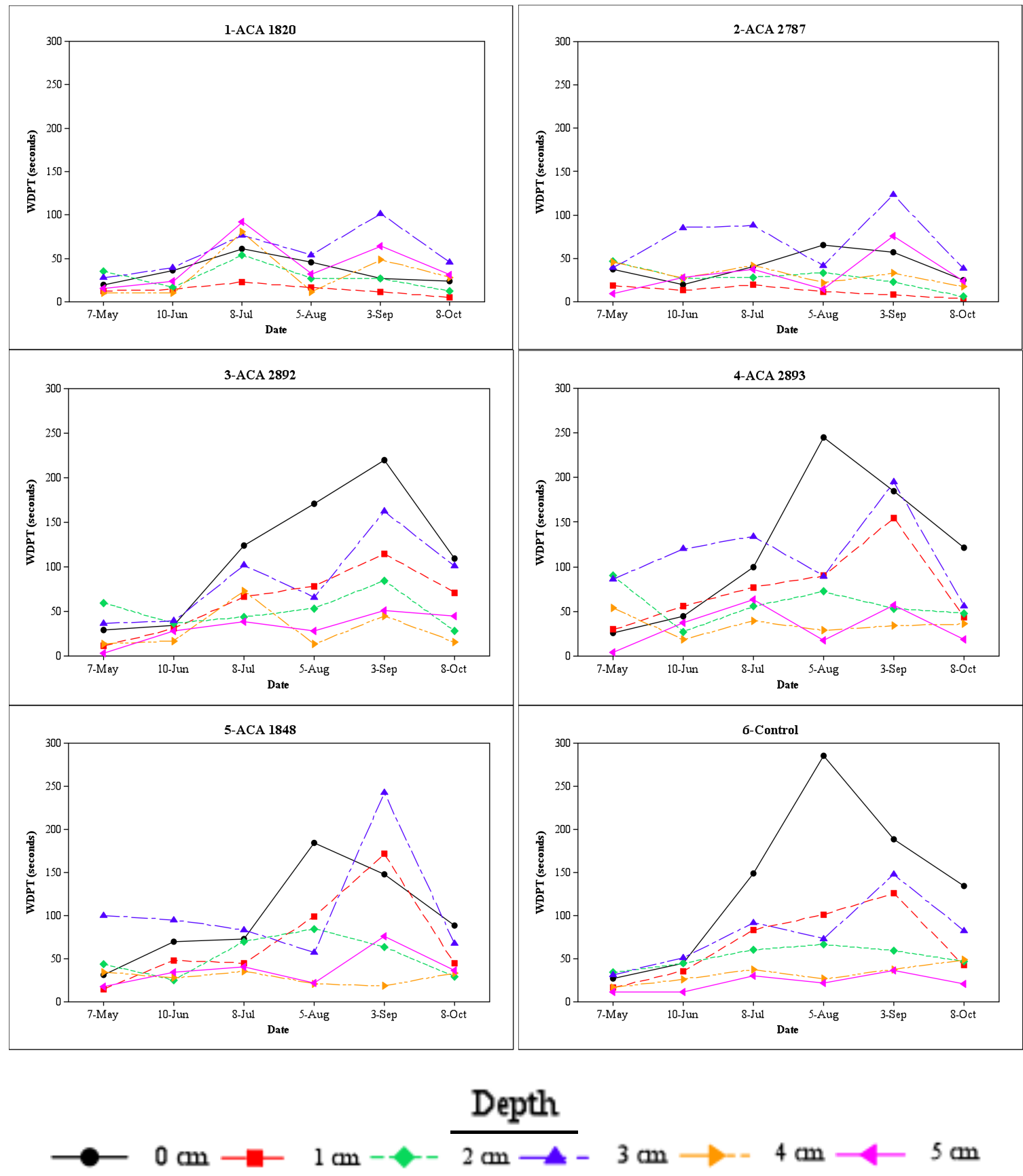

Figure 16. Comparison of wetting agent treatment trends at individual depths during Trial I (2008). 
During Trial II control soil hydrophobicity (WDPT) did not change significantly when each depth was compared individually (Figure 17). After the initial application period, there was an immediate drop in soil hydrophobicity in treatments 1-ACA 1820 and 7-CP (60day) at depths $0 \mathrm{~cm}$ to $2 \mathrm{~cm}$. This drop in soil hydrophobicity was delayed by one application period ( 1 month) at depths $3 \mathrm{~cm}$ to $6 \mathrm{~cm}$. More frequent applications with Cascade Plus 6-CP (10day) showed no delay in surfactant effectiveness. Wetting agent treatment 11-2079336 was delayed only at $3 \mathrm{~cm}$ and wetting agent treatment $12-$ 2079337 was delayed at $2 \mathrm{~cm}$ to $4 \mathrm{~cm}$.

Because wetting agent treatment 6-CP (10day) did not have a one month delay in wetting agent effectiveness as did 7-CP (60day), we cannot say that this delay was caused by time alone. The delay in the reduction of soil hydrophobicity in soil deeper than $1 \mathrm{~cm}$ to $2 \mathrm{~cm}$ is indicative of the number of applications of a particular wetting agent necessary to minimize soil hydrophobicity in the top $2 \mathrm{~cm}$ of soil before reacting with the soil beneath. Initial downward movement of wetting agents is therefore limited to the severity of soil hydrophobicity at the surface (Feng et al. 2002). 

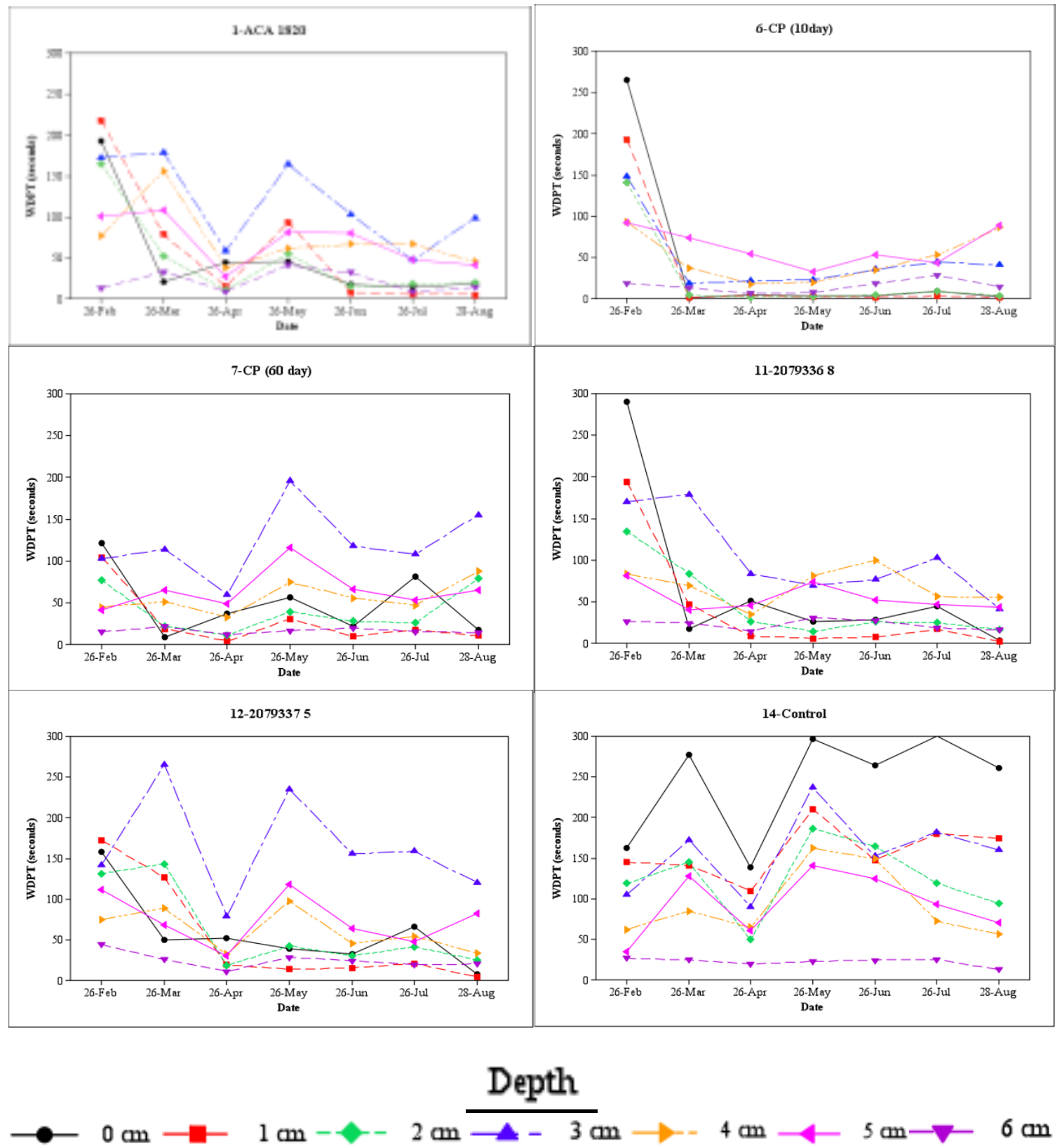

Figure 17. Comparison of top five performing wetting agents at individual depths during Trial II (2009). 


\section{Phytotoxicity: Trial I}

Visual turf quality rated 1 to 9 improved in plots treated with wetting agent compared with untreated control plots during Trial I (Figure 18). Untreated plots had the highest turf quality at the start of the experiment but ended up having the lowest turf quality at the end of the experiment.

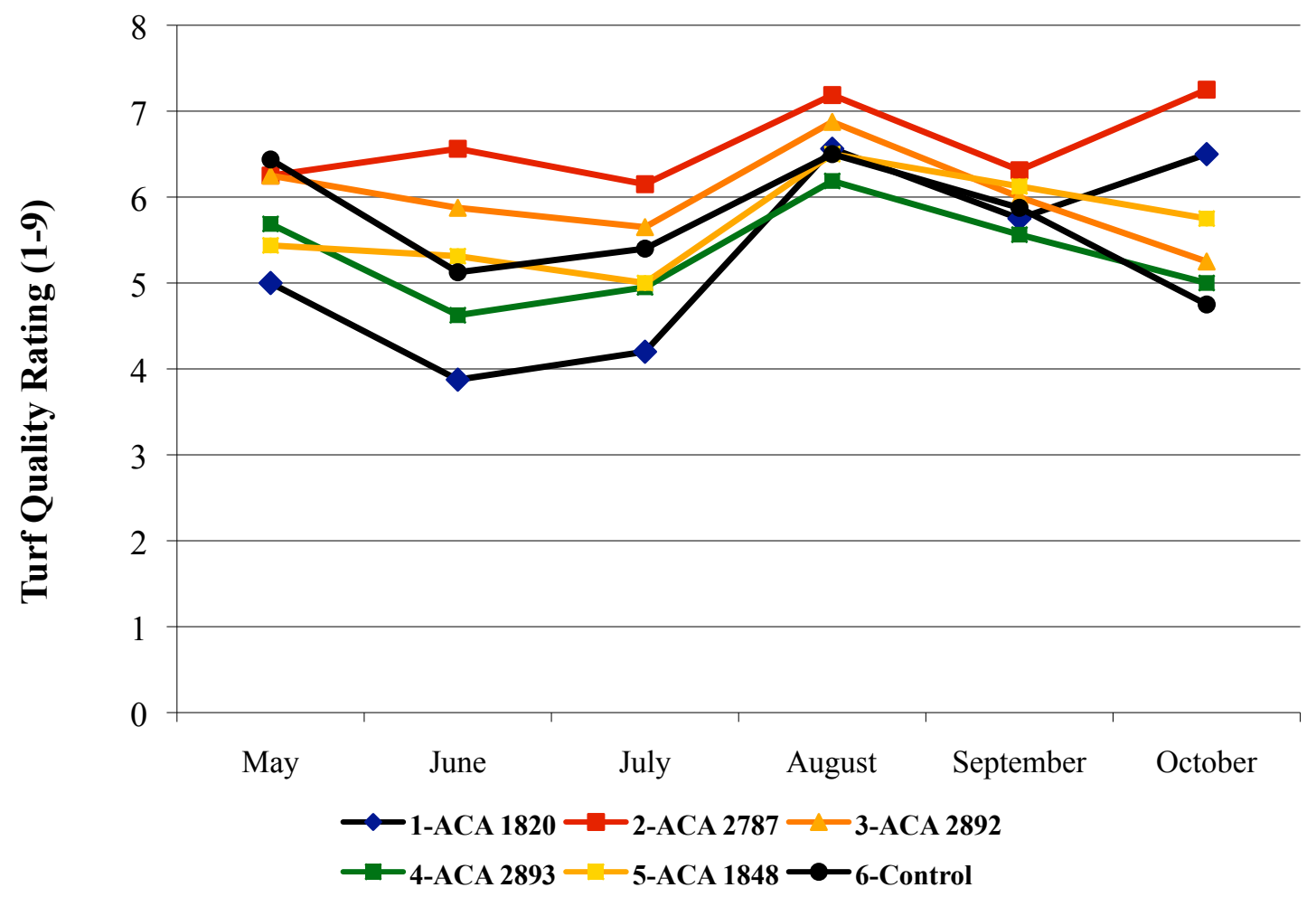

Figure 18. Turf quality rating (1-9) data during Trial I (2008). $1=$ yellow and $9=$ dark green.

During June and July 2008, plots treated with 2-ACA 2787) were significantly (P $<0.05$ ) higher in turf quality than plots treated with 1-ACA 1820 (Table 9). At the end of the experiment, plots treated with 2 -ACA 2787 were significantly $(\mathrm{P}<0.05)$ greater in turf quality than untreated plots and plots treated with 4-ACA 2893. 
Table 9. Turf Quality Rating (1-9) during Trial I (2008) ${ }^{\mathrm{a}}$

\begin{tabular}{l|cccccc}
\hline Treatment & May & June & July & August & September & October \\
\hline 1-ACA 1820 & $5.0 \mathrm{a}$ & $3.9 \mathrm{a}$ & $4.2 \mathrm{a}$ & $6.6 \mathrm{a}$ & $5.8 \mathrm{a}$ & $6.5 \mathrm{ab}$ \\
2-ACA 2787 & $6.3 \mathrm{a}$ & $6.6 \mathrm{~b}$ & $6.2 \mathrm{~b}$ & $7.2 \mathrm{a}$ & $6.3 \mathrm{a}$ & $7.3 \mathrm{~b}$ \\
3-ACA 2892 & $6.3 \mathrm{a}$ & $5.9 \mathrm{ab}$ & $5.7 \mathrm{ab}$ & $6.9 \mathrm{a}$ & $6 \mathrm{a}$ & $5.3 \mathrm{ab}$ \\
4-ACA 2893 & $5.7 \mathrm{a}$ & $4.6 \mathrm{ab}$ & $4.9 \mathrm{ab}$ & $6.2 \mathrm{a}$ & $5.6 \mathrm{a}$ & $5 \mathrm{a}$ \\
5-ACA 1848 & $5.4 \mathrm{a}$ & $5.3 \mathrm{ab}$ & $5 \mathrm{ab}$ & $6.5 \mathrm{a}$ & $6.1 \mathrm{a}$ & $5.8 \mathrm{ab}$ \\
6-Control & $6.4 \mathrm{a}$ & $5.1 \mathrm{ab}$ & $5.4 \mathrm{ab}$ & $6.5 \mathrm{a}$ & $5.9 \mathrm{a}$ & $4.8 \mathrm{a}$ \\
\hline
\end{tabular}

${ }^{a}$ Monthly averages of turf quality ratings performed weekly on a 1-9 scale with $9=$ dark green, and $1=$ yellow turf. Means with the same letter within a column are not significantly different from each other using ANOVA (Analysis of Variance) and Tukey's Confidence Interval (Appendix B); P<0.05.

The percent spread of localized dry spots (LDS) was tracked May through July of 2008 (Figure 19). On average localized dry spots worsened in June but improved slightly in July.

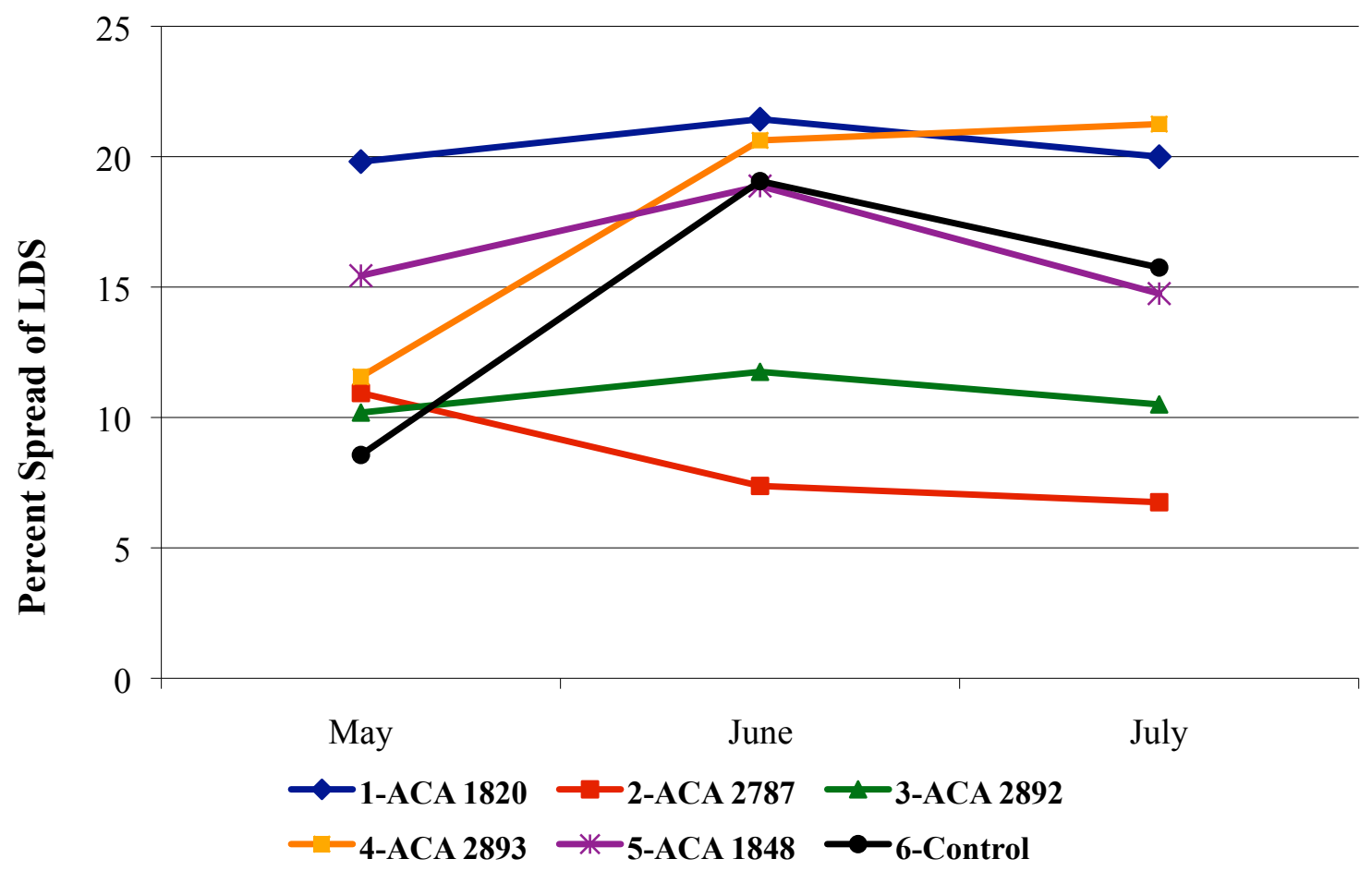

Figure 19. Percent spread of localized dry spots (LDS) during Trial I (2008). 
During June, when spread of LDS for the untreated plots was worse, plots treated with 2-ACA 2787 showed significantly $(\mathrm{P}<0.05)$ less area covered with localized dry spots, compared with plots treated with 1-ACA 1820 (Table 10). No other significant differences in LDS were detected.

Table 10. Percent spread of localized dry spots (LDS) during Trial I (2008) ${ }^{\mathrm{a}}$

\begin{tabular}{lccc}
\hline Treatment & May & June & July \\
\hline 1- ACA 1820 & $19.8 \mathrm{a}$ & $21.4 \mathrm{a}$ & $20 \mathrm{a}$ \\
2- ACA 2787 & $10.9 \mathrm{a}$ & $7.4 \mathrm{~b}$ & $6.8 \mathrm{a}$ \\
3- ACA 2892 & $10.2 \mathrm{a}$ & $11.8 \mathrm{ab}$ & $10.5 \mathrm{a}$ \\
4- ACA 2893 & $11.6 \mathrm{a}$ & $20.6 \mathrm{ab}$ & $21.3 \mathrm{a}$ \\
5- ACA 1848 & $15.4 \mathrm{a}$ & $18.9 \mathrm{ab}$ & $14.8 \mathrm{a}$ \\
6-Control & $8.6 \mathrm{a}$ & $19.1 \mathrm{ab}$ & $15.8 \mathrm{a}$ \\
Significance & $\mathrm{ns}$ & $*$ & $\mathrm{~ns}$ \\
\hline
\end{tabular}

${ }^{a}$ Monthly averages of percent LDS performed weekly. Means with the same letter within a column are not significantly different from each other using ANOVA (Analysis of Variance) and Tukey's Confidence Interval (Appendix B); ns, ${ }^{*}$, and ${ }^{* *}$ represent $\mathrm{P}>0.05, \mathrm{P}<0.05$, and $\mathrm{P}<0.01$, respectively.

\section{Phytotoxicity: Trial II}

Chlorophyll content index values, measured using a chlorophyll meter, declined during Trial II (2009) but eventually recovered to original levels (Figure 20). This is not unusual as Bentgrass has a tendency to decline during the Summer (Carrow, 1996).

Chlorophyll values changed in relation to month rather than by treatment (Figure 20). Poa Annua seed heads may have confounded these measurements. During the course of Trial II, the growth of a lighter green grass (Poa Annua) was observed along with an even lighter color seed head (almost yellow) in the experimental plots. 


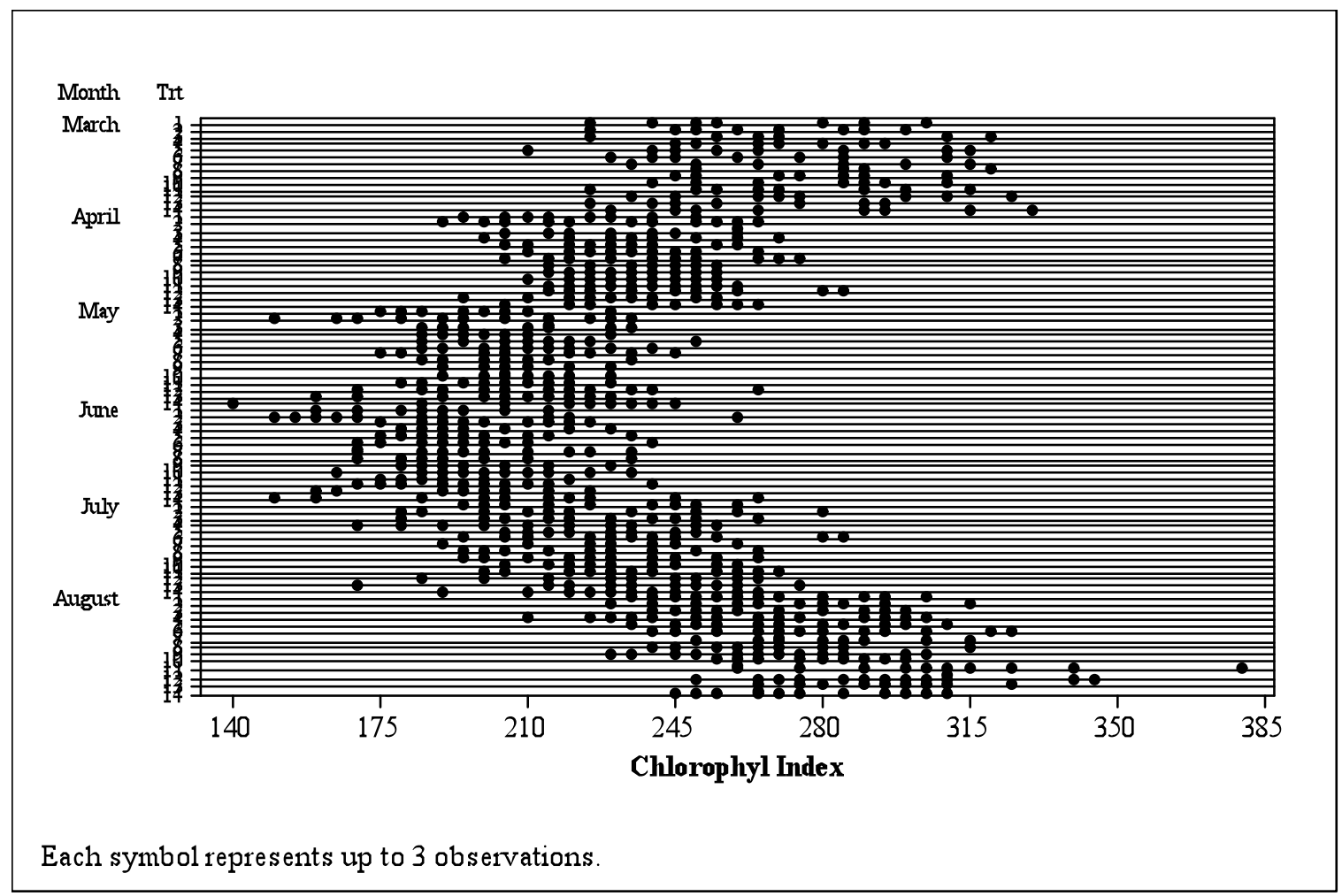

Figure 20. Chlorophyll index values arranged themselves by month rather than by wetting agent treatment (Trt).

Table 11 shows the ANOVA table comparing index values by wetting agent treatment. The treatment (Trt) p-value (probability of no significant difference) shows that there is no chance of phytotoxicity being related to treatment in this experiment. The error term in this model or mean square (MS) for error, used in dividing MS for treatment to calculate $\mathrm{F}$ (frequency) and $\mathrm{p}$ from a F distribution, is not large compared with the other terms in the model and indicates that if there were a significant difference in index values in relation to treatment, the model should have detected it. Since no significant affect of treatment on chlorophyll index was detected for Trial II, further analysis was unnecessary. 
Table 11. ANOVA table for chlorophyll index values ${ }^{\text {a }}$

\begin{tabular}{|l|c|c|c|c|c|}
\hline Source & DF & SS & MS & F & P \\
\hline Trt & 13 & 1936 & 149 & 0.13 & 1.000 \\
\hline Error & 70 & 77841 & 1112 & & \\
\hline Total & 83 & 79777 & & & \\
\hline
\end{tabular}

${ }^{\mathrm{a}} \mathrm{Trt}=$ treatment, $\mathrm{DF}=$ degrees of freedom, $\mathrm{SS}=$ Sum of Squares, MS = Mean Square, $\mathrm{P}=$ probability

\section{$\underline{\text { Irrigation Audit }}$}

A catch can irrigation audit as outlined by Kieffer (2007) was performed to test irrigation distribution uniformity (DU). Catch can lower quartile distribution uniformity $\left(D U_{l q}\right)$ for the entire system was found to be 57.2 percent (Figure 21) which is slightly above what is considered poor for rotor head sprinkler systems (Kieffer and Huck, 2008). However, actual irrigation uniformity in the root zone has been found to be significantly higher than catch can uniformity in sand based golf greens (Kieffer, 2007). 


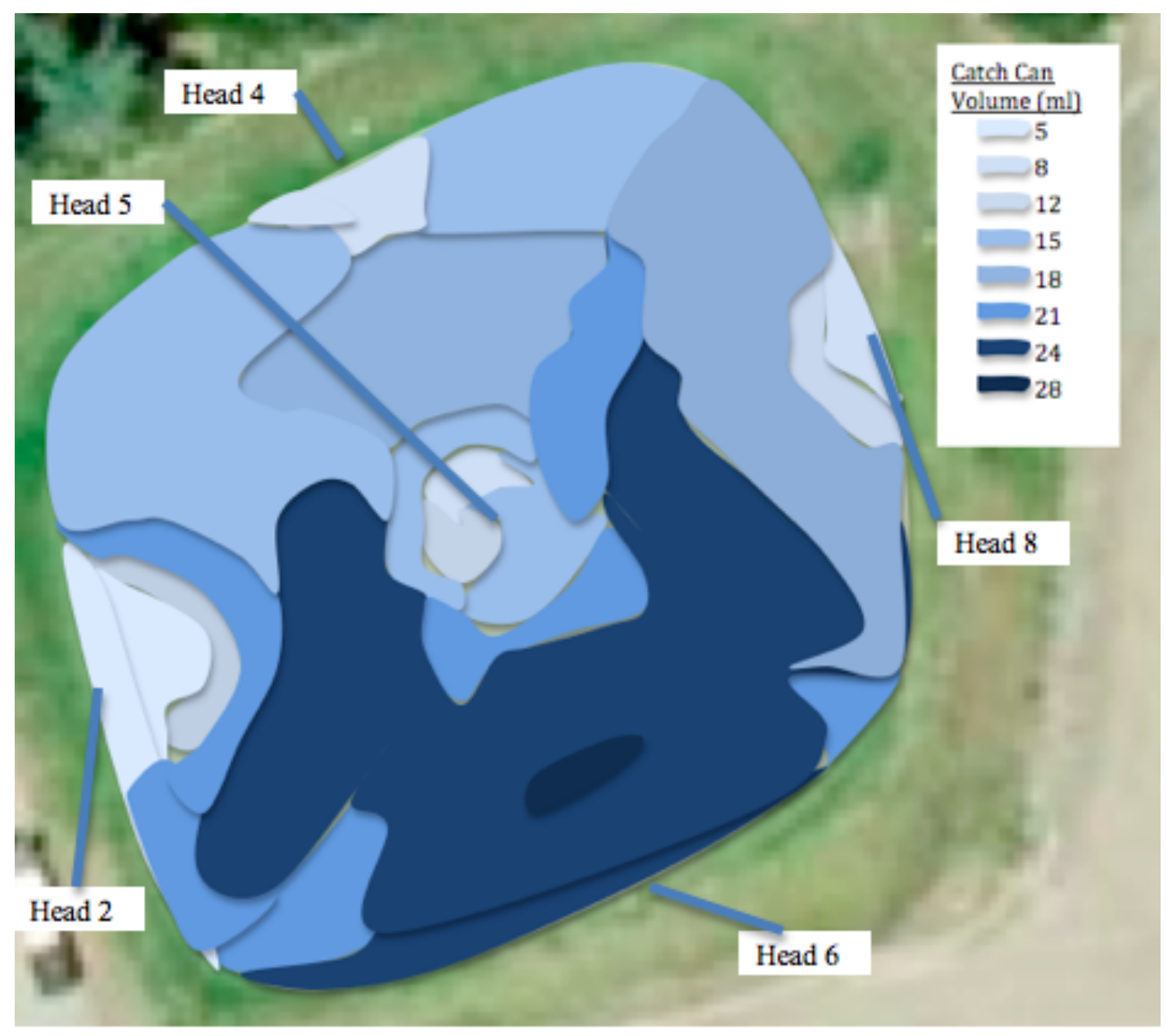

Figure 21. Spatial variability map of catch can lower quartile distribution uniformity $\left(\mathrm{DU} \mathrm{lq}_{\mathrm{lq}}\right)$.

The area between heads 5 and 6 had the highest individual distribution uniformity and the area between heads 5 and 2 had the lowest (Table 12). The area between heads 5 and 4 as well as between heads 5 and 8 cover the majority of the experimental area. The average lower quartile distribution of these two zones is 60.5 percent. 
Table 12. Precipitation data from irrigation heads during irrigation audit ( $\mathrm{mm}$ per hour).

\begin{tabular}{|c|c|c|c|c|}
\hline $\begin{array}{l}\text { Gauge } \\
\text { no. }\end{array}$ & $\begin{array}{l}\text { Area between } \\
\text { head } 5 \text { and } 2\end{array}$ & $\begin{array}{l}\text { Area between } \\
\text { head } 5 \text { and } 4\end{array}$ & $\begin{array}{l}\text { Area between } \\
\text { head } 5 \text { and } 6\end{array}$ & $\begin{array}{l}\text { Area between } \\
\text { head } 5 \text { and } 8\end{array}$ \\
\hline 1 & 8 & 20 & 24 & 18 \\
\hline 2 & 16 & 18 & 12 & 16 \\
\hline 3 & 12 & 11 & 16 & 20 \\
\hline 4 & 16 & 11 & 16 & 20 \\
\hline 5 & 16 & 18 & 16 & 16 \\
\hline 6 & 16 & 18 & 20 & 28 \\
\hline 7 & 20 & 26 & 22 & 24 \\
\hline 8 & 28 & 20 & 24 & 24 \\
\hline 9 & 24 & 18 & 24 & 24 \\
\hline 10 & 24 & 20 & 26 & 24 \\
\hline 11 & 24 & 18 & 26 & 24 \\
\hline 12 & 20 & 20 & 28 & 24 \\
\hline 13 & 24 & 18 & 28 & 20 \\
\hline 14 & 24 & 20 & 28 & 16 \\
\hline 15 & 24 & 20 & 24 & 16 \\
\hline 16 & 20 & 18 & 24 & 16 \\
\hline 17 & 12 & 9 & 24 & 12 \\
\hline 18 & 12 & 9 & 24 & 12 \\
\hline 19 & 8 & 9 & 24 & 12 \\
\hline 20 & 2 & 9 & 24 & 8 \\
\hline $\mathrm{DU}_{\mathrm{lq}}$ & $48 \%$ & $56.8 \%$ & $70.5 \%$ & $64.2 \%$ \\
\hline
\end{tabular}

With the exception of the area between heads 5 and 6 , irrigation was least in the catch cans furthest away from head 5 and greatest 6 to 8 feet away from head 5 (Figure 22). The area between heads 5 and 6 had a different distribution of irrigation than the areas between the other irrigation heads. Though wind was minimal in severity during the irrigation audit, there was a slight wind ( 2 meters per second) which may have contributed to the difference. 


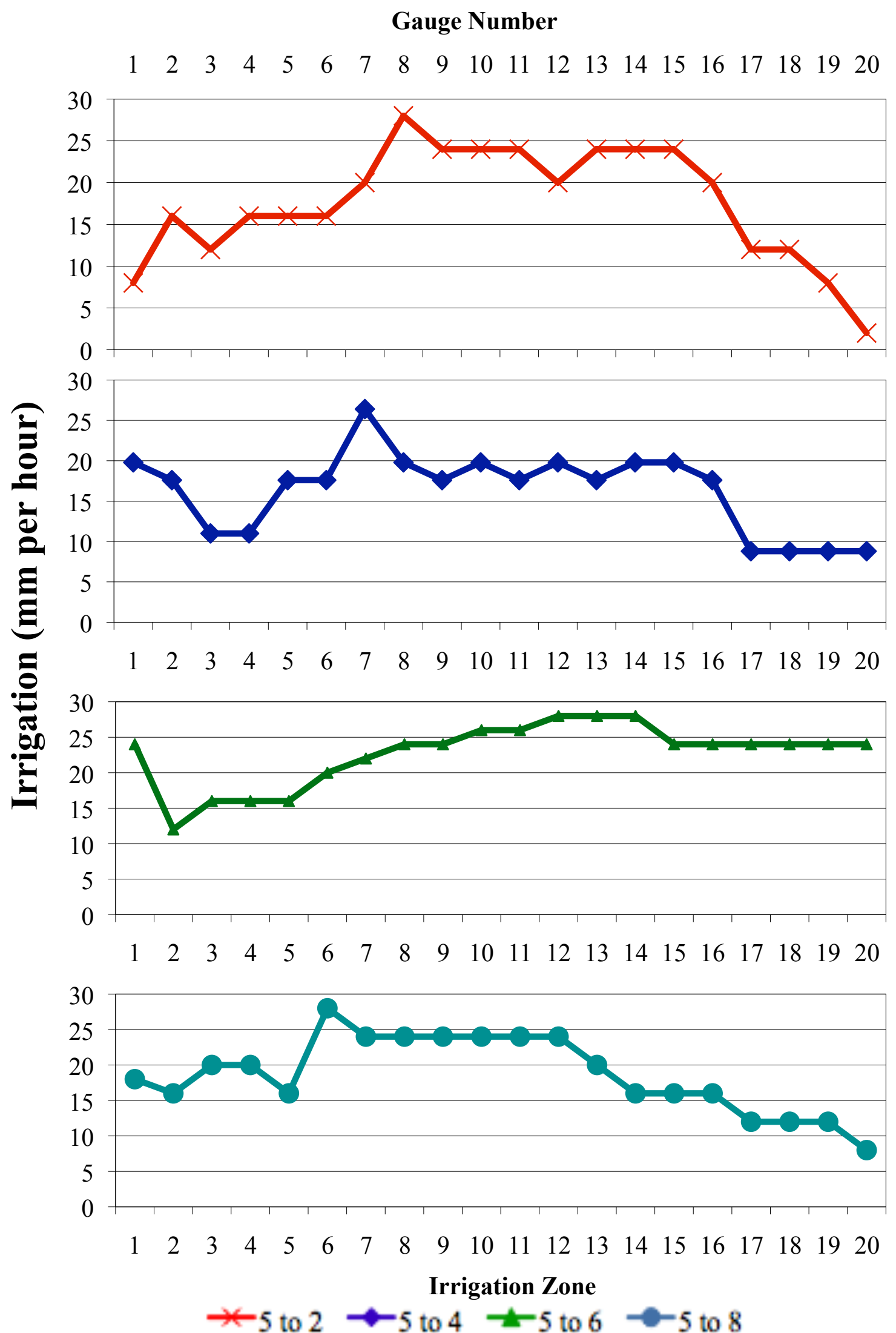

Figure 22. Results from irrigation audit. 


\section{$\underline{\text { Volumetric Water Content }}$}

Percent volumetric water content (VWC) in the surface $5.8 \mathrm{~cm}$ of the green's root zone was found to be influenced by wetting agent treatment validating the same discovery made by Karnok (2008). Table 13 shows the significance of wetting agent treatments in comparison to one each other (Appendix E).

Table 13. Percent VWC during Trial II (2009)

\begin{tabular}{lclc}
\hline Treatment & Mean & Treatment & Mean \\
\hline 1-ACA 1820 & $16.9 \mathrm{abc}$ & 8-MAGNUS & $17.3 \mathrm{abcd}$ \\
2-ACA 2787 & $15.2 \mathrm{a}$ & 9-MAG+Duplex & $18.5 \mathrm{bc}$ \\
3-ACA 2892 & $17.6 \mathrm{abcd}$ & $10-2079336-5$ & $17.8 \mathrm{bc}$ \\
4-ACA 2893 & $17.2 \mathrm{abc}$ & $11-2079336-8$ & $17.9 \mathrm{bc}$ \\
5-ACA 1848 & $19.2 \mathrm{~cd}$ & $12-2079337-5$ & $16.4 \mathrm{ab}$ \\
6-CP 10day & $21.8 \mathrm{e}$ & $13-2079337-8$ & $19.4 \mathrm{cde}$ \\
7-CP 60day & $17.5 \mathrm{abcd}$ & $14-$ Control & $19.2 \mathrm{~d}$ \\
\hline
\end{tabular}

${ }^{a}$ Means with the same letter are not significantly different according to Tukey's confidence interval.

The VWC for treatment 6- CP(10day) was significantly greater $(\mathrm{p}<0.05)$ than the VWC for all other treatments and was highly significantly greater $(\mathrm{p}<0.001)$ than 1ACA 1820, 4-ACA 2893, and the control (Figure 23).

Algae was observed on the green and in replicate 3 in April and again in June of 2009. The green was dried down below field capacity prior to the 16 April and the 25 June readings to control the algae. With the exception of 16 April 2009, wetting agent treatment 6-CP (10day) remained at or above field capacity (Figure 23). None of the treatments reached permanent wilting point $(4.4 \%)$. 


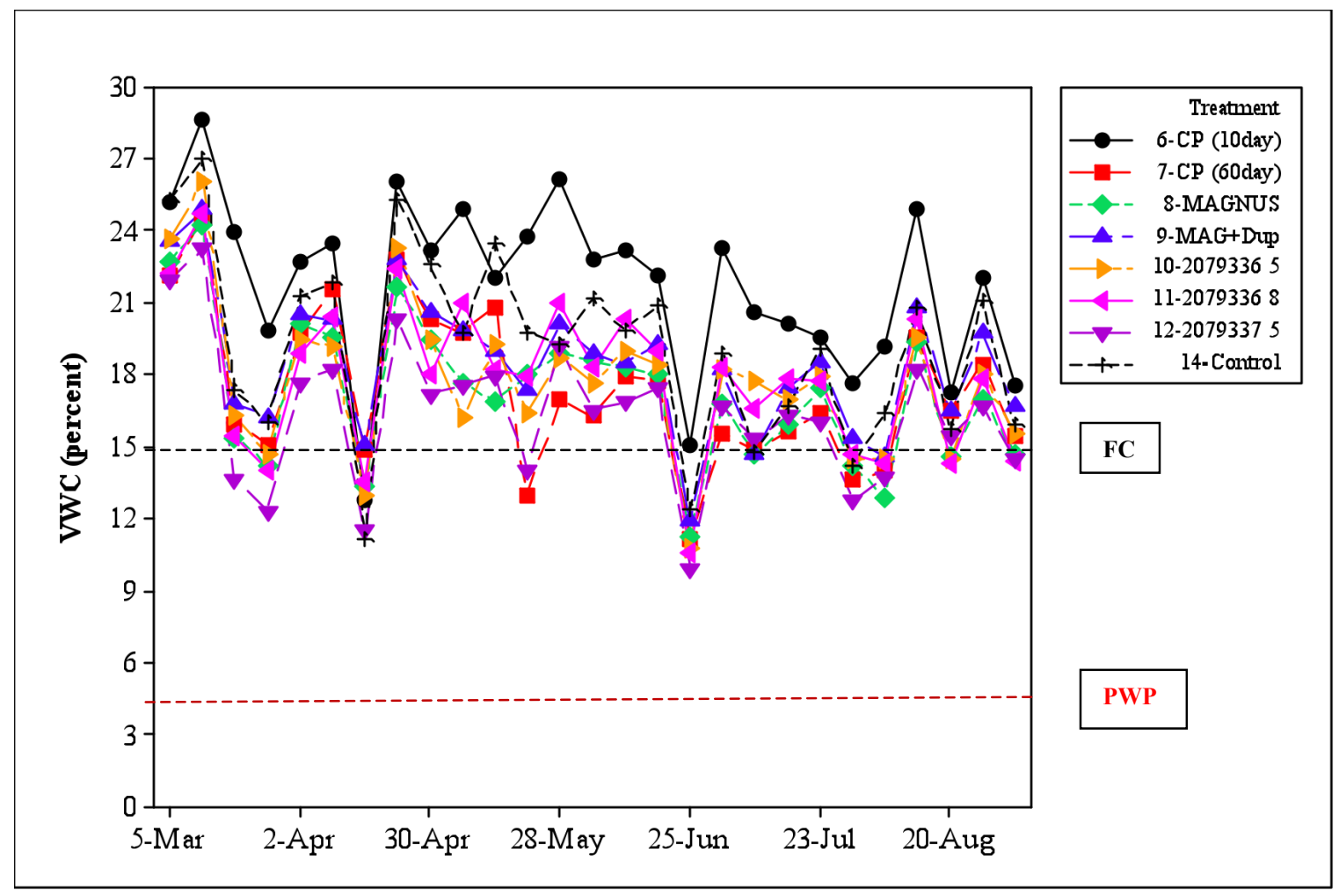

Figure 23. Treatments with significantly lower percent volumetric water content (VWC) than treatment with highest VWC (6-CP10day). FC = field capacity, PWP = permanent wilting point.

Average VWC for 2-ACA 2787 was significantly lower than average VWC values for 5-ACA 1848, 6-Cascade Plus (10day), 9-Magnus+Duplex, 10-2079336 (5ml), 11-2079336 (8ml), 13-2079337 (8ml) and the control (Figure 24). Wetting agent treatment 2-ACA 2787 stayed below 20 percent VWC.

The VWC for wetting agent treatment 12-2079337 (5ml) was also significantly lower than the VWC for 5-ACA 1848. Increasing the application rate of 2079337 from 5 $\mathrm{ml}$ per $110 \mathrm{ml}$ to $8 \mathrm{ml}$ per $110 \mathrm{ml}$ significantly $(\mathrm{p}<0.05)$ improved irrigation efficiency. The VWC for 12-2079337 (5 ml) was significantly less than the mean VWC for 132079337 (8 ml) and the control. 


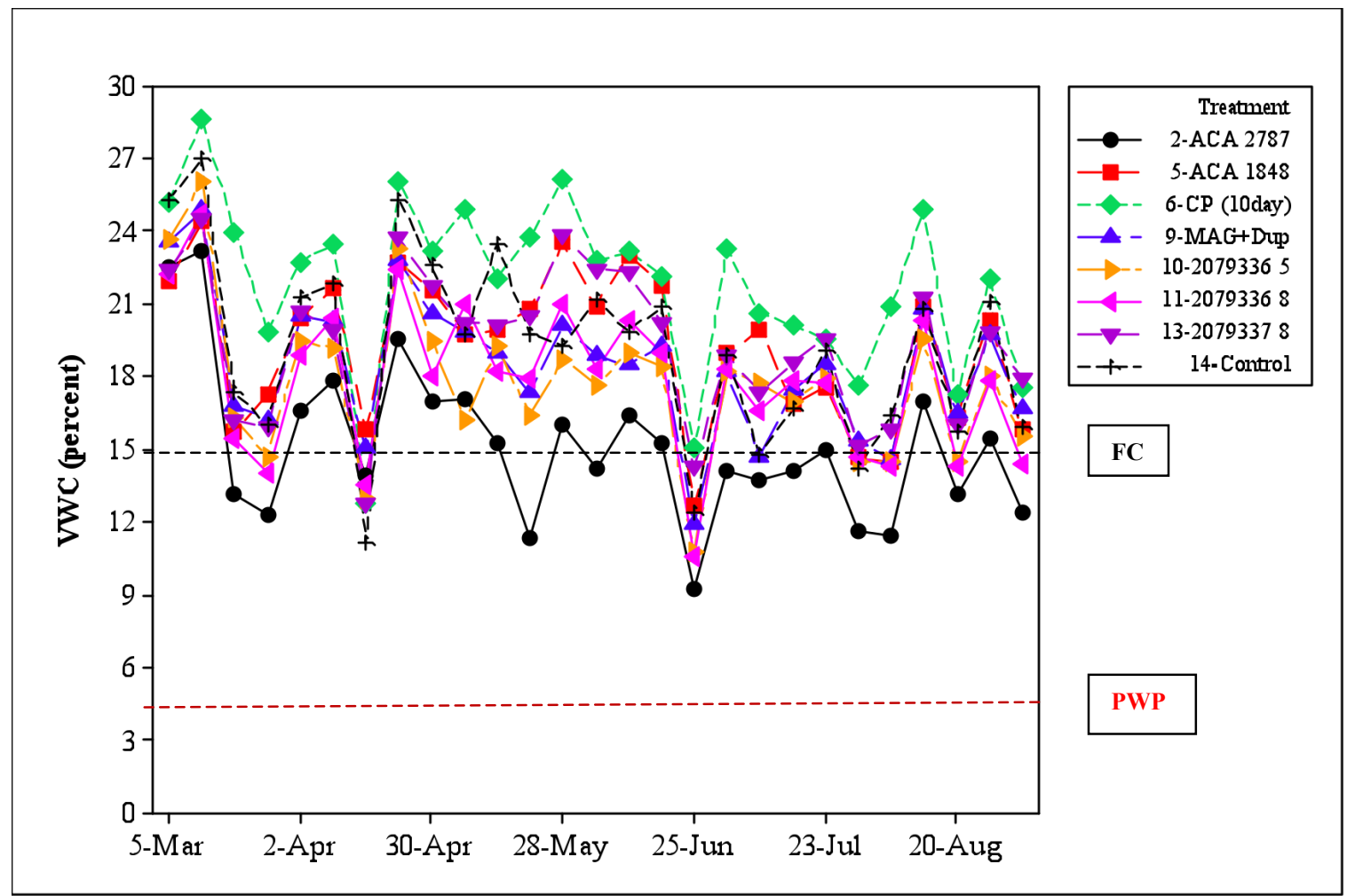

Figure 24. Treatments with significantly greater percent volumetric water content (VWC) than treatment with the lowest VWC (2-ACA 2787). FC = field capacity, PWP = permanent wilting point. 


\section{CHAPTER 5}

\section{CONCLUSION}

The objectives of this study were to evaluate the effectiveness of thirteen wetting agents in alleviating soil hydrophobicity, localized dry spots and phytotoxicity. Secondary objectives were to calculate the correct volumetric water content (VWC) irrigation range on the sand based putting green used during this study, and to determine which wetting agent treatment retains the greatest amount of moisture (VWC) in the root zone.

During both trials, all the wetting agent treatments significantly $(\mathrm{p}<0.05)$ lowered water droplet penetration time (WDPT) compared with the control except for treatments 3-ACA 2982, 4-ACA 2983, and 5-ACA 1848. Increasing application frequency of Cascade Plus from 60 days to 10 days significantly $(\mathrm{p}<0.001)$ reduced soil hydrophobicity (WDPT). Increasing application amount reduced WDPT significantly (p $<0.002)$ for 2079336 but not significantly $(\mathrm{p}=0.593)$ for 2079337 .

Analysis of WDPT by depth confirmed that soil in the surface $3 \mathrm{~cm}$ of green rootzones is significantly more hydrophobic than at greater depths. The reduction of WDPT at depths greater than $2 \mathrm{~cm}$ was delayed one application period (month) by all wetting agents except for wetting agent treatment 6-CP(10day) confirming that the initial downward movement of wetting agents is limited to the severity of soil hydrophobicity at the surface.

During Trial II, a separation in WDPT appeared among the surfactants when monthly average high temperatures rose from 19.9 degrees in April to 22.3 degrees Celsius in May. This separation in soil hydrophobicity represents the intensification of 
soil hydrophobicity and the effectiveness of the wetting agent treatments. A small increase in temperature followed by an increase in evapotranspiration, caused irreversible dry down in the soil (soil hydrophobicity) when water moisture values fell below a critical soil water content (Dekker et al., 1998).

During Trial I, wetting agent treatment 2-ACA 2787 significantly decreased the spread of localized dry spots compared with wetting agent treatment 1-ACA 1820. Phytotoxicity as measured using turf quality ratings (1-9) showed an improvement in plots treated with wetting agents during Trial I. Phytotoxicity as measured from chlorophyll index showed no difference in treated plots from the control during Trial II. This indicates that minimal phytotoxicity was caused by the wetting agent treatments.

The ideal volumetric water content (VWC) for the surface $3 \mathrm{~cm}$ of the green used in this study was found to be between 15.4 and 9.9 percent. There was a significant effect of wetting agent treatment on volumetric water content in the surface $5.8 \mathrm{~cm}$ of the green. Wetting agent treatment 6-Cascade Plus (10 day) had the highest VWC (moisture in the rootzone) than all other treatments and was also significantly greater than treatments 7Cascade Plus (60 day), 8-Magnus, 9-Magnus+Duplex, 10-2079336 (5ml), 11-2079336 (8ml), 12-2079337 (5ml) and the control.

One may wish to further study the effects of wetting agent treatment 2-ACA 2787 on minimizing the spread of localized dry spots or the effectiveness of 3-ACA 2982, 4ACA 2983, and 5-ACA 1848 in reducing soil hydrophobicity at greater application rates. 


\section{BIBLIOGRAPHY}

Alexander, M. 1977. Introduction to Soil Microbiology. $2^{\text {nd }}$ ed. Krieger Publishing Company, Malabar, FL.

ASTM D6836-02 (Reapproved 2008), "Standard Test Methods for Determination of the Soil Water Characteristic Curve for Desorption Using Hanging Column, Pressure Extractor, Chilled Mirror Hygrometer, or Centrifuge," ASTM International.

Carey, K. and E. Gunn. 2004. Field evaluation of experimental soil surfactants: 2004 season. Guelph Turfgrass Institute Research Reports 18:24-37.

Carrow, R. 1996. Summer decline of bentgrass greens. Golf Course Management 64(6): 51-56.

Couch, H. 1995. Diseases of Turfgrasses $3^{\text {rd }}$ ed. Krieger Publishing Company, Malabar, F.L.

Coyne, M. 1999. Soil Microbiology: An exploratory approach. Delmar Publishers, New York.

Dekker, L., C. Ritsema, K. Oostindie, and O. Boersma. 1998. Effect of drying temperature on the severity of soil water repellency. Soil Science 163(10): 780-796.

Feng, G., J. Letey, L. Wu. 2002. The influence of two surfactants on infiltration into a water repellent soil. Soil Science Society of America Journal 66: 361-367.

Fidanza, M., F. Wong, B. Martin, and S. McDonald. 2007. Treating fairy ring with fungicides, new soil surfactant. Golf Course Management 75(5): 121-125.

Franco, C., P. Michelsen, and J. Oades. 2000. Amelioration of water repellency: application of slow-release fertilisers to stimulate microbial breakdown of waxes. Journal of Hydrology 231-232: 342-351.

Franklin, M., S. McCann, and S. Kostka. 2005. Evaluating turfgrass performance after surfactant application in a wettable and a non-wettable soil. International Turfgrass Society Research Journal 10:85-86.

Fuhr, F. and D. Sauerbeck. 1966. Uptake of Straw Decomposition Products By Plants. The Use of Isotopes in Soil Organic Matter Studies: Supplement to the Journal of Applied Radiation and Isotopes. Pergamon Press, p. 73.

Gibeault, V., S. Cocker-ham, J. Henry, and J. Meyer. 1989. California Turfgrass Culture. University of California Cooperative Extension. 39(3-4): 1-9. 
Horne, D. and J. McIntosh. 2000. Hydrophobic compounds in sands from New Zealand; extraction, characterization and proposed mechanisms for repellency expression. Journal of Hydrology 231-232:35-46.

Hummel, H. 1993. Rationale for the Revisions of the USGA Green Construction Specifications. USGA Green Section Record 32(2):7-21.

Jaramillo, D., L. Dekker, and C. Ritsema, J. Hendrickx. 2000. Occurrence of soil water repellency in arid and humid climates. Journal of Hydrology 231-232:105-111.

Karnok, K., J. Everett, and K. Tan. 1993. High pH treatments and the alleviation of soil hydrophobicity on golf greens. Agronomy Journal 85:983-986.

Karnok, K. and K. Tucker. 2001. Wetting agent treated hydrophobic soil and its effect on color, quality, and root growth of creeping bentgrass. International Turfgrass Society Research Journal 9: 537-541.

Karnok, K., and K. Tucker. 2002. Water-repellent soils. Part I: Where are we now? Golf Course Management 70(6): 59-62.

Karnok, K., X. Kang, and K. Tucker. 2004. Wetting agents: what are they and how do they work? Golf Course Management 72(6):84-86.

Karnok, K. and K. Tucker. 2008. Using wetting agents to improve irrigation efficiency. Golf Course Management 76(6): 109-110.

Kieffer, D. 2007. Managing soil moisture on golf greens using a portable wave reflectometer. Paper presented at the $28^{\text {th }}$ Annual Irrigation Show, San Diego, CA December 9-11, 2007.

Kieffer, D. and M. Huck. 2008. A comparison of fairway distribution uniformity computed with catch can data and with soil moisture data from three sampling depths. Paper presented at the $29^{\text {th }}$ Annual Irrigation Show, Anaheim, CA November 2-4, 2008.

King, P. 1981. Comparison of methods for measuring severity of water repellence of sandy soils and assessment of some factors that affect its measurement. Aust. J. Soil Res. 19:275-285.

Kostka, S. 2000. Amelioration of water repellency in highly managed soils and the enhancement of turfgrass performance through the systematic application of surfactants. Journal of Hydrology 231-232: 359-368.

Kostka, S., J. Cisar, J. Short, S. Mane. 1997. Evaluation of soil surfactants for the management of soil water repellency in turfgrass. International Turfgrass Society Research Journal. 8:485-494. 
Leelamanie, D., J. Karube, and A. Yoshida. 2008. Characterizing water repellency indices: Contact angle and water drop penetration time of hydrophobized sand. Soil Science and Plant Nutrition 54:179-187.

Leelamanie, D., J. Karube, and A. Yoshida. 2008. Relative humidity effects on contact angle and water drop penetration time of hydrophobized fine sand. Soil Science and Plant Nutrition. 54:695-700.

Leinauer, B., D. Karcher, T. Barrick, Y. Ikemura, H. Hubble, and J. Makk. 2007. Water repellency in sandy rootzones treated with wetting agents. USGA Turfgrass and Environmental Research Online 6(6): 1-9. TGIF Record Number: 123686.

Miller, C. 2001. Comparing wetting agents: long-term vs. short-term. Golf Course Management 69 (4): 60-64.

Miyamoto, S. 1985. Effects of wetting agents on water infiltration into poorly wettable sand, dry sod, and wettable soils. Irrigation Science. 6:271-279.

O'Brien P. and C. Hartwiger. 2003. Aeration and topdressing for the $21^{\text {st }}$ century. USGA Green Section Record 41(2): 1-6.

Stribley, D. and D. Read. 1980. The biology of mycorrhiza in the ericaceae. VII. the relationship between mycorrhizal infection and the capacity to utilize simple and complex organic nitrogen sources. New Phytologist 86:365-371.

Tan, K. 1998. Principles of Soil Chemistry. $3^{\text {rd }}$ ed. Marcel Dekker, Inc., New York.

Throssel C. 2005. GCSAA-USGA wetting agent evaluation: update. Golf Course Management 73(8): 71-79.

Tucker, K., K. Karnock, D. Radcliffe, G. Landry, Jr., R. Roncadori, and K. Tan. 1990. Localized dry spots as caused by hydrophobic sands on bentgrass greens. Agronomy Journal 82:549-555.

Turgeon, A. 2005. Turfgrass Management. $7^{\text {th }}$ ed. Pierson Prentice Hall, N.J., p 8 -82.

Wallis, M., D. Horne, and K. McAuliffe. 1989. A survey of dry patch and its management in New Zealand golf greens: 2. Soil core results and irrigation interaction. New Zealand Turf Management Journal 3:15-17.

Wilkinson, J. and R. Miller. 1978. Investigation and treatment of localized dry spots on sand golf greens. Soil Science Society of America Journal 70:299-304. 